NBER WORKING PAPER SERIES

\title{
OPTIMAL HARVEST WITH MULTIPLE FISHING ZONES, ENDOGENOUS PRICE AND GLOBAL UNCERTAINTY
}

\author{
Jose Pizarro \\ Eduardo S. Schwartz \\ Working Paper 28732 \\ http://www.nber.org/papers/w28732
NATIONAL BUREAU OF ECONOMIC RESEARCH
1050 Massachusetts Avenue
Cambridge, MA 02138
April 2021

The views expressed herein are those of the authors and do not necessarily reflect the views of the National Bureau of Economic Research.

NBER working papers are circulated for discussion and comment purposes. They have not been peer-reviewed or been subject to the review by the NBER Board of Directors that accompanies official NBER publications.

(C) 2021 by Jose Pizarro and Eduardo S. Schwartz. All rights reserved. Short sections of text, not to exceed two paragraphs, may be quoted without explicit permission provided that full credit, including $(\odot$ notice, is given to the source. 
Optimal Harvest with Multiple Fishing Zones, Endogenous Price and Global Uncertainty

Jose Pizarro and Eduardo S. Schwartz

NBER Working Paper No. 28732

April 2021

JEL No. G10,G13,G31,Q20,Q22

\begin{abstract}
$\underline{\text { ABSTRACT }}$
The literature on the optimal harvest of fisheries has concentrated on a single fishing area with biomass uncertainty and to a lesser degree also with price uncertainty. We develop and implement a stochastic optimal control approach to determine the harvest that maximizes the value of a fishery participating in a global market, where all the considered harvesting zones sell their production. This market is characterized by an inverse demand function, which combines an exogenous demand shock and the aggregate harvesting of all zones. Accordingly, a fishery's harvest will be affected by the global demand shocks and the harvesting in all the competing zones through the global selling price. In addition, we decompose the biomass uncertainty into local and global biomass shocks. Through global biomass shocks, the model provides enough flexibility to acknowledge for correlation in the biomass shocks faced by the multiple perhaps adjacent areas. When we compare our global framework with an alternative where the individual zones are aggregated into a single optimizing fishery we find that competition will increase the global harvest and consequently reduced the resource price.
\end{abstract}

Jose Pizarro

University of British Colombia

2053 Main Mall

Vancouver, BC V6T 1 Z2

Canada

jose.pizarro@sauder.ubc.ca

Eduardo S. Schwartz

Anderson School of Management

University of California, Los Angeles

110 Westwood Plaza

Los Angeles, CA 90095

and Simon Fraser University, Vancouver, Canada

and also NBER

eduardo.schwartz@anderson.ucla.edu 


\section{Introduction}

The rapid integration of natural resource markets that has occurred in the last few decades has changed the landscape for fisheries. International trade has continuously expanded fueled by trade liberalization and technological changes. Fisheries have also experienced these changes.

We can now consider the fish market as a global market. Products harvested in South America, Africa or Europe are widely available across the world for consumption. This supply expansion, driven by globalization, has intensified the competition faced by local fisheries. Consequently, it is reasonable to think that a value-maximizing fishery will be concerned about global conditions when deciding its optimal harvest.

In this paper, we propose a novel framework to find the optimal harvest of a fishery operating in a global market. We develop and implement a stochastic optimal control framework to determine the optimal harvest that maximizes the value of a fishery participating in a global market, where all the considered harvesting zones sell their production. This market is characterized by an inverse demand function, which combines a stochastic exogenous demand factor and the aggregate harvesting of all zones. Accordingly, a fishery's harvest will be affected by the global demand shocks and the harvesting in all the competing zones through the global selling price. In essence, each fishery optimizes its harvest taking into account the optimal harvest of all the other zones. When no fishery has an incentive to deviate from its optimal strategy a Nash equilibrium is obtained.

A fishery operating in a particular zone will also face uncertainty on the dynamics of its biomass. In particular, we decompose the biomass uncertainty into local and global biomass shocks. Through global biomass shocks, the model provides enough flexibility to acknowledge for correlation in the biomass shocks faced by the multiple perhaps adjacent areas.

In summary, our model includes global and local uncertainty. That is, market-wide shocks that will affect all the considered fisheries and local shocks that will only affect a single fishery. This consideration will allow us to understand how each uncertainty source affects the fishery's optimal policy.

Since the model considers multiple zones competing on the amount of harvest they will extract, and the price is determined by the aggregate harvest, the global price and its dynamics are an endogenous result of the model, intertwined with the harvesting policies of the modeled zones and the multiple sources of uncertainty.

To the best of our knowledge, our paper is the first to propose a global market setting with various zones and multiple sources of uncertainty. Several papers, including Nøstbakken (2006), Poudel et al. (2013), Kvamsdal et al. (2016) and Pizarro and Schwartz (2021) consider a single fishery facing multiple sources of uncertainty, including price uncertainty, but do 
not expand to a setting that allows understanding the effects of competition and global uncertainty. Pindyck (1984) presented a model with a similar inverse demand function, but without global demand uncertainty or multiple zones competing.

A key contribution of the paper is that we apply the framework to a real group of fisheries in defined geographical zones. We obtain data for the Alaska and British Columbia halibut fishery. The data includes time series for the halibut biomass, total harvest (landings) and price. We use this data to estimate all the required parameters of the model. We select these areas because of data availability. We collected data from several sources, including the International Pacific Halibut Commission (IPHC), the National Oceanic and Atmospheric Administration (NOAA) and Fisheries and Oceans Canada (DFO).

The model and the solution algorithm are developed with an arbitrary number of zones. But to illustrate its implementation we consider a setting with only two zones. Many of the interesting features of the model can be observed in this setting. We focus on two particular cases, the first is denoted Symmetric Case and the second is denoted Asymmetric Case. In the Symmetric Case, we consider two zones with comparable biomass, South Alaska (2C) and British Columbia (2B). In the Asymmetric Case, we consider two zones with very different biomass, Alaska (2C, 3 and 4) and British Columbia (2B). We believe that these two cases will allow us to illustrate the key economic and financial trade-offs of the model.

Another contribution of our paper is to show that global competition is indeed a fundamental force driving a fishery's optimal harvest choices. To reach this conclusion we compare our global framework with an alternative where the individual zones are aggregated into a single optimizing fishery, thus abstracting from all competition effects. We obtain significantly different results. In particular, we show that competition will increase the global harvest and consequently reduced the resource price, overall benefiting consumers.

The model is solved using a value-function iteration algorithm. The solution approach solves for the optimal dynamic harvesting policy of the representative fishery in each zone separately. This fishery will take the optimal harvesting policy of the competing zones as given and decide its optimal policy as the best response to this set of functions. Once the problem is solved for all zones, the optimal policies are updated, and the problem is solved again for each fishery with the updated set of policies. The algorithm stops when no significant changes are made to the policy of any of the studied zones.

The model allows us to study how the optimal harvest relates to the multiple state variables in our model, which are, the biomass in each zone and the exogenous demand factor. The model also shows how the harvest will optimally evolve with stochastic changes in the state variables. Based on the optimal policy, it is possible to simulate the dynamics of the biomass, subject to global and local stochastic shocks and optimal harvesting. This 
analysis illustrates how the biomass in each zone will evolve over a specific time horizon.

The paper proceeds as follows. The general valuation model is presented in Section 2. Section 3 provides a detailed estimation of the model parameters for the Alaska and the British Columbia halibut fishery. Section 4 presents the model results for both the symmetric and asymmetric cases. Section 5 shows the impact of global competition on the optimal harvesting policy. Finally, Section 6 provides our concluding remarks. Details on the solution algorithm are provided in the Appendix.

\section{A Valuation Model of Marine Fisheries Rights with Global Uncertainty}

In this section, we present an economic model to study fisheries valuation in a global framework. We consider multiple geographical zones on which the fish specie of interest is available. In each zone, a representative fishery maximizes the value of the resource by choosing the optimal annual harvest, taking into account that in the other zones representative fisheries will also be doing the same.

We consider $N$ different zones where the resource is harvested independently by the local representative fishery. The dynamic of the biomass for the zone $i \in\{1,2, \ldots, N\}$ is:

$$
\Delta I_{i, t+1}=G_{i}\left(I_{i, t}\right)-q_{i, t}+I_{i, t}\left(\sigma_{i} \epsilon_{i, t+1}+\phi_{i} \eta_{t+1}\right)
$$

where $I_{i, t}$ is the biomass at year $t$ in zone $i, G_{i}\left(I_{i, t}\right)$ is the annual expected rate of growth of the biomass, $q_{i, t}$ is the annual harvesting rate, $\epsilon_{i, t}$ is the local biomass shocks, which are assumed to be i.i.d. standard normal, $\sigma_{i}$ is the volatility of the unanticipated local shocks to the resource stock.

We also introduce global shocks to the biomass $\eta_{t+1}$, which are common to all the zones and assumed to be i.i.d. standard normal. $\phi_{i}$ is the sensitivity of zone $i$ to the unanticipated global shocks to the resource stock. The local and global shocks are assumed to be mutually orthogonal, although the existence of the global shocks will induce correlation in the unexpected changes in the biomass across zones. The covariance between the shocks in zone $i$ and $j$ is:

$$
\operatorname{Cov}\left[\sigma_{i} \epsilon_{i, t+1}+\phi_{i} \eta_{t+1}, \sigma_{j} \epsilon_{j, t+1}+\phi_{j} \eta_{t+1}\right]=\phi_{i} \phi_{j}
$$

as a result, the correlation coefficient between the shocks in zone $i$ and $j$ is: 


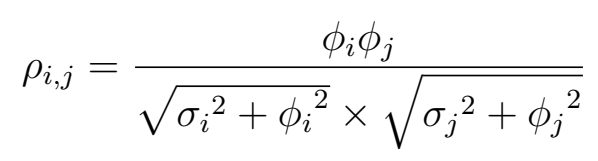

Note that when the $\left\{\sigma_{1}, \sigma_{2}, \ldots, \sigma_{N}\right\}$ are equal to 0 , the correlation is equal to 1 and when the $\left\{\phi_{1}, \phi_{2}, \ldots, \phi_{N}\right\}$ are equal to zero the correlation is 0. As in Kvamsdal et al. (2016), Sims et al. (2018) and Pizarro and Schwartz (2021), the growth rate of the biomass is assumed to follow a logistic function:

$$
G_{i}\left(I_{i, t}\right)=\gamma_{i} I_{i, t}\left(1-\frac{I_{i, t}}{I_{i}^{\text {max }}}\right)
$$

Combining the dynamics of the biomass and harvest of each zone, the dynamics of global biomass $I_{t}=\sum_{i=1}^{N} I_{i, t}$ is:

$$
\Delta I_{t+1}=\sum_{i=1}^{N}\left[G_{i}\left(I_{i, t}\right)-q_{i, t}+I_{i, t}\left(\sigma_{i} \epsilon_{i, t+1}+\phi_{i} \eta_{t+1}\right)\right]
$$

re-writing Equation (5) as:

$$
\Delta I_{t+1}=\sum_{i=1}^{N} G_{i}\left(I_{i, t}\right)-\sum_{i=1}^{N} q_{i, t}+\sum_{i=1}^{N} I_{i, t} \sigma_{i} \epsilon_{i, t+1}+\sum_{i=1}^{N} I_{i, t} \phi_{i} \eta_{t+1}
$$

We denote $q_{t}=\sum_{i=1}^{N} q_{i, t}, G\left(I_{t}\right)=\sum_{i=1}^{N} G_{i}\left(I_{i, t}\right), \omega_{i, t}=\frac{I_{i, t}}{I_{t}}, \hat{\epsilon_{t+1}}=\sum_{i=1}^{N} \omega_{i, t} \sigma_{i} \epsilon_{i, t+1}$ and $\eta_{t+1}=\sum_{i=1}^{N} \omega_{i, t} \phi_{i} \eta_{t+1}$, thus the global biomass dynamics can be written as:

$$
\Delta I_{t+1}=G\left(I_{t}\right)-q_{t}+I_{t}\left(\hat{\epsilon}_{t+1}+\hat{\eta}_{t+1}\right)
$$

where $\hat{\epsilon}_{t+1}$ is an i.i.d. normal with mean zero and volatility:

$$
\sigma_{t}^{\hat{\epsilon}}=\sqrt{\sum_{i=1}^{N} \omega_{i, t}^{2} \sigma_{i}^{2}}
$$

and $\hat{\eta}_{t+1}$ is an i.i.d. normal with mean zero and volatility:

$$
\sigma_{t}^{\hat{\eta}}=\sqrt{\sum_{i=1}^{N} \omega_{i, t}^{2} \phi_{i}^{2}}
$$

The annual harvest of each zone is sold in a global market at the global market price. This price is determined by the aggregate harvest from the $N$ zones, $q_{t}$, and the global inverse demand curve: 


$$
P_{t}=X_{t}\left(\sum_{i=1}^{N} q_{i, t}\right)^{-\kappa}=X_{t} q_{t}^{-\kappa}
$$

where $P_{t}$ is the unit fish price at year $t, X_{t}$ is an exogenous stochastic demand factor and $\kappa \in(0,1)$ is the demand slope. The exogenous stochastic component of the demand follows the process:

$$
\Delta \ln X_{t}=\mu_{X}+\sigma_{X} \nu_{t}
$$

where $\mu_{X}$ is the annual expected in the logarithm of $X_{t} . \nu_{t}$ is assumed to be an i.i.d. standard normal and $\sigma_{X}$ is the demand shocks volatility. Demand and biomass shocks are assumed to be orthogonal.

Note that the global price at which each representative fishery can sell its harvest depends on the harvest of all fisheries. Hence, when each fishery optimizes its harvest, it has to take into account the optimal harvest of all the other fisheries and its effect on the global price. Figure 1 illustrates the market organization.

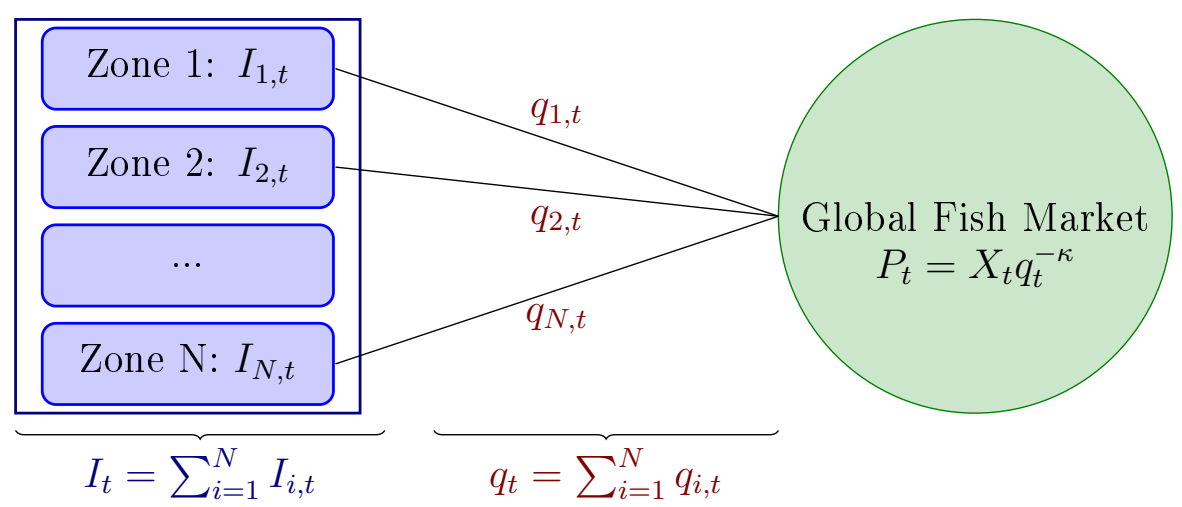

Global Biomass Aggregate Harvest

Figure 1: Market Organization.

We now focus on the problem solved by an infinitely-lived value-maximizing fishery, with enough installed capacity for the range of harvests considered, and the right to harvest in a particular zone $i$. The fishery's annual cash flow from harvesting $]^{1}$ is equal to:

$$
\pi_{i}\left(I_{i, t}, P_{t}, q_{i, t}\right)=P_{t} \times q_{i, t}-c_{i}\left(q_{i, t}\right)
$$

Using the price definition presented in Equation (9), we can re-write the representative fishery's profit as:

\footnotetext{
${ }^{1}$ For simplicity we abstract from taxes and depreciation in this presentation of the model.
} 


$$
\pi_{i}\left(I_{i, t}, X_{t}, q_{1, t}, \ldots, q_{N, t}\right)=X_{t}\left(\sum_{i=1}^{N} q_{i, t}\right)^{-\kappa} \times q_{i, t}-c_{i}\left(q_{i, t}\right)
$$

The operating cost function of harvesting $q_{i, t}, c\left(q_{i, t}\right)$, is:

$$
c_{i}\left(q_{i, t}\right)=c_{0}^{i}+c_{1}^{i} \times q_{i, t}
$$

where $c_{0}^{i}$ is the fixed cost and $c_{1}^{i}$ is the variable cost. All these parameters correspond to the fishery operating in area $i$. The cost function parameter $c_{0}^{i}$ captures also the fixed cost paid by the fishery to remain open in years without harvest.

Equation (12) shows a key economic mechanism of our model, the interdependence of the different zones, specifically, how the choices made in other zones impact the profits of the fishery operating in zone $i$ through their effect on the global price. Hence, when the fishery in area $i$ decides its optimal harvest, it will take into account the harvest from other areas being sold in the global market.

This interconnection between the different harvesting zones will require the fishery in zone $i$ to consider the harvesting policies in all the alternative areas when deciding its optimal policy, and consequently, the state variables of each zone will need to be considered in the fishery's problem besides the aggregate exogenous demand shock.

For the infinitely lived representative fishery in area $i$, the present value of future expected cash flows, for the space state $\left\{I_{1, t}, \ldots, I_{N, t}, X_{t}\right\}$ and a given set of harvesting policies $q_{i, t}=$ $q_{i}\left(I_{1, t}, \ldots, I_{N, t}, X_{t}\right), i \in 1, . ., N$, is:

$$
\begin{aligned}
& H_{i}\left(I_{1, t}, \ldots, I_{N, t}, X_{t}, q_{i}\left(I_{1, t}, \ldots, I_{N, t}, X_{t}\right)\right)= \\
& \mathbb{E}_{t}\left[\sum_{\tau=t}^{\infty} \frac{1}{(1+r)^{\tau-t}} \pi_{i}\left(I_{1, \tau}, \ldots, I_{N, \tau}, X_{\tau}, q_{i}\left(I_{1, \tau}, \ldots, I_{N, \tau}, X_{\tau}\right)\right)\right]
\end{aligned}
$$

where $r$ is the fishery's risk-adjusted cost of capital. As all considered fisheries harvest a common specie and compete in the same market we assume that their cost of capital is the same.

A value-maximizing fishery will choose the optimal harvesting policy $q_{i}^{*}\left(I_{1, t}, \ldots, I_{N, t}, X_{t}\right)$, that is, the harvesting policy that maximizes the value of the fishery for the current state space.

As mentioned, the revenues of a fishery operating in zone $i$ directly depend on the harvesting policies of the fisheries operating in the rest of the zones. Hence, each fishery anticipates the optimal harvests for all the other fisheries and chooses its optimal harvest to maximize its value. This is, when maximizing the firm's value, the fishery in zone $i$ takes the set of 
functions $q^{*} / q_{i}^{*}=\left\{q_{j}^{*}\left(I_{1, t}, \ldots, I_{N, t}, X_{t}\right) \forall j \in\{1,2, \ldots, N\}-i\right\}$ as known and optimally selects its harvesting policy $q_{i}^{*}\left(I_{1, t}, \ldots, I_{N, t}, X_{t}\right)$.

The fishery in area $i$, taking the set of optimal policies $q^{*} / q_{i}^{*}$ as known, solves the following Bellman equation:

$$
\begin{aligned}
& V_{i}\left(I_{1, t}, \ldots, I_{N, t}, X_{t}\right)= \\
& \max _{q_{i}^{*} \geq 0}\left\{\pi_{i}\left(I_{1, t}, \ldots, I_{N, t}, X_{t}, q_{i}^{*}\right)+\frac{1}{1+r} \mathbb{E}_{t}\left[V_{i}\left(I_{1, t+1}, \ldots, I_{N, t+1}, X_{t+1}\right)\right]\right\}
\end{aligned}
$$

where $V_{i}\left(I_{1, t}, \ldots, I_{N, t}, X_{t}\right)$ is the value of the fishery in area $i$, under the optimal policy $q_{i}^{*}$ for the current state space $\left\{I_{1, t}, \ldots, I_{N, t}, X_{t}\right\}$.

As $q^{*} / q_{i}^{*}$ is the set of optimal policies, the optimal policy for the fishery in zone $i$ becomes the best response to the optimal strategy of the fisheries in the other zones, therefore, the set of harvesting policies represents a Nash Equilibrium, as any unilateral deviation from this harvesting policy will be sub-optimal.

Second, the model will allow us to incorporate competition in global markets, thus we can understand how a fishery operating in different levels of competition will change its behavior when facing demand, local biomass or global biomass shocks. This model allow us to understand how a fishery with a positive influence in the price will differ from a small zone that operates as a pure price taker as its influence in the price is overall marginal.

The proposed model has positive policy potential as it will help regulators understand how to tackle global shocks and local shocks, and if it is optimal to regulate zone by zone or to have a global approach. All these potential contributions are discussed in the remainder of this paper. In Section 3 we estimate all the parameters of the model using real data of the Pacific halibut fishery. Section 4 shows the results for the harvesting policy and the fishery's value for a global market. Section 5 present several applications of our model in different settings to address the previously presented contributions. Finally, Section 6 concludes. A description of the approach taken to solve the model is included in the Appendix.

\section{Parameter Estimation for the Pacific Halibut Fishery}

To illustrate the implementation of the methodology presented in the previous section, we calibrate and solve the model for the Pacific halibut. This area is ideal to test our model as its setting is consistent with our assumptions, multiple geographical zones that harvest a unique specie and the proximity of the multiple selling points allow us to consider the existence of a unique global market for the resource on this geographical area. 
We consider the regulatory areas determined by the International Pacific Halibut Commission (IPHC). The IPHC was established in 1923 by a convention between Canada and the U.S. for the preservation of the Pacific halibut fishery, and monitors the resource over the regulatory areas presented in Figure 2. The IPHC is our first source of data, as we obtain the biomass assessments from its annual reports.

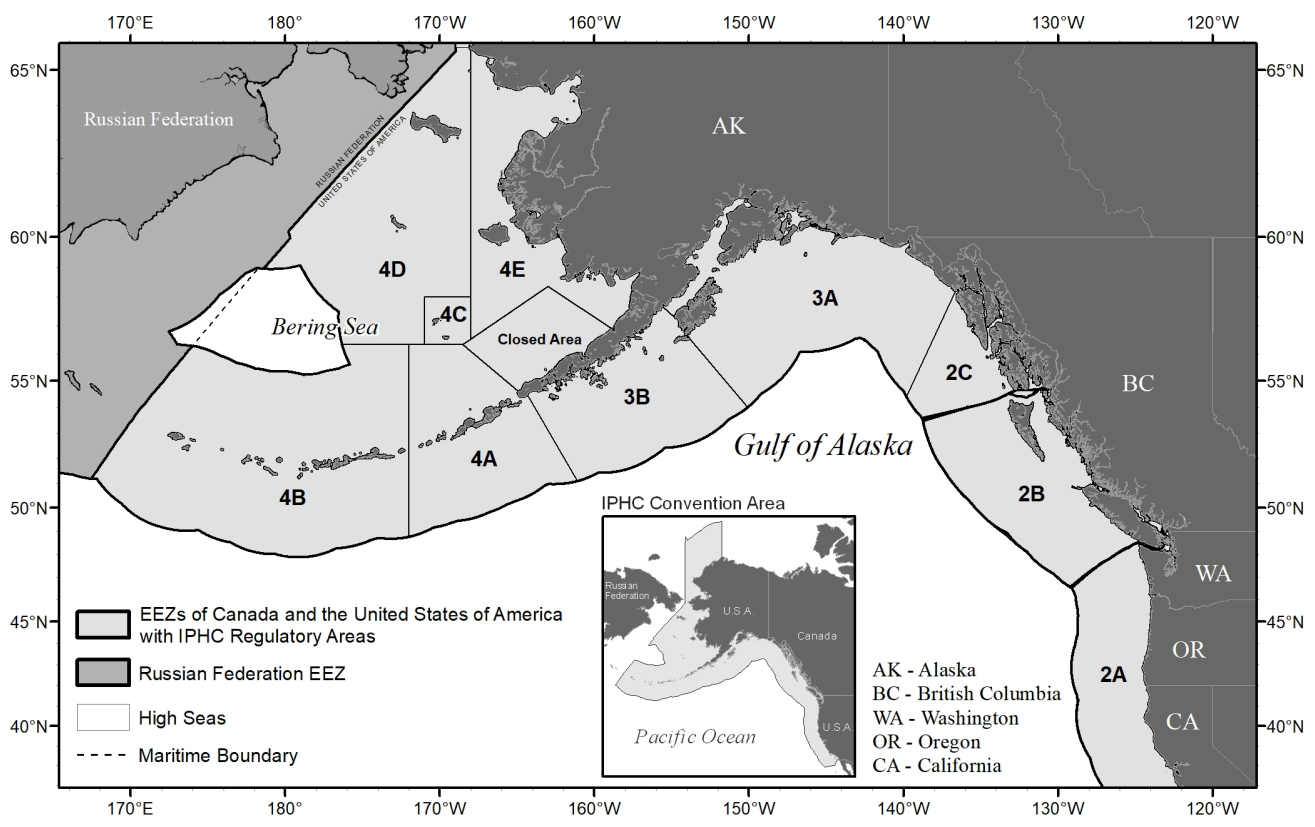

Figure 2: International Pacific Halibut Commission (IPHC) Regulatory Areas. Source: IPHC.

Our second source of data is the Department of Fisheries and Oceans of Canada (DFO), specifically, we use the British Columbia halibut landings, price data and financial reports published on its site ${ }^{2}$. Our third source of data is the National Oceanic and Atmospheric Administration (NOAA), we use the Alaska halibut landings and price data published on its $\operatorname{sit} 3$

Although our model is designed to deal with any number of zones, for illustrative purposes we will focus on $N=2$. In particular, we consider two cases. First, when two zones have similar levels of their biomass, which we call Symmetric Case. Second, when the two zones have very different levels of their biomass, which we call Asymmetric Case. These cases encompass most of the potential applications of the model and will facilitate the understanding of the key economic and financial mechanisms.

In the following subsections, we present the estimations for the parameters for the specified

\footnotetext{
2 https://www.dfo-mpo.gc.ca/index-eng.htm

3 https://www.noaa.gov/
} 
cases of the halibut biomass dynamics for each considered zone, the price dynamics and the cost function.

\subsection{Symmetric Case: South Alaska and British Columbia}

For the symmetric case, we consider two zones of similar size: the South Alaska zone (2C) and the British Columbia zone (2B).

\subsubsection{South Alaska (2C) and British Columbia (2B) Halibut Biomass Dynamics Parameters}

To estimate the biomass dynamics we use the stock assessments provided by Stewart and Hicks (2017) and Stewart and Webster (2017), which although approximate, is the closest proxy to its true magnitude. The symmetric case biomass assessment of each zone is presented in Panel A of Figure 3. Panel B shows the share of the total biomass of each zone.
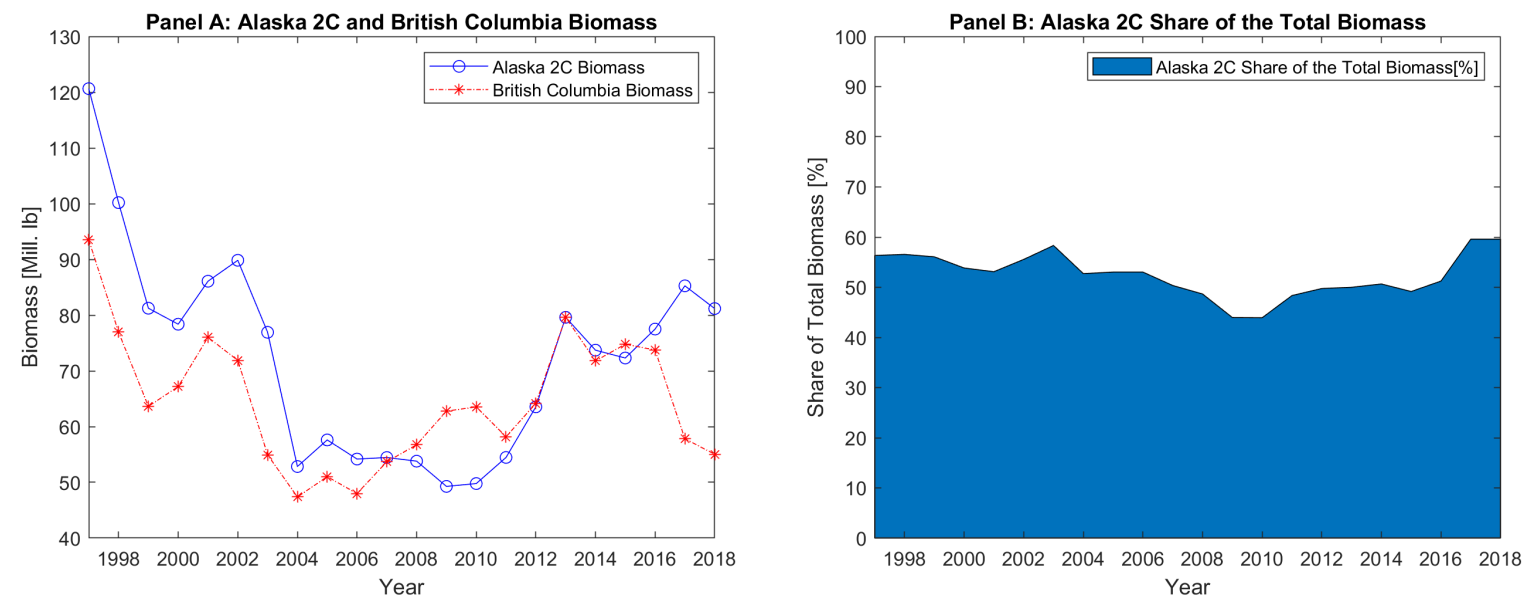

Figure 3: Biomass of the South Alaska zone (2C) and the British Columbia zone (2B). Source: International Pacific Halibut Commission (IPHC).

Harvesting data was obtained from the Department of Fisheries and Oceans of Canada (DFO) ${ }^{4}$ website and the National Oceanic and Atmospheric Administration (NOAA) web$\operatorname{sit}^{5}$. The annual harvesting for the South Alaska zone $(2 \mathrm{C})$ and the British Columbia zone (2B) are presented in Figure 4.

${ }^{4}$ http: //www.dfo-mpo.gc.ca

5 foss.nmfs.noaa.gov 


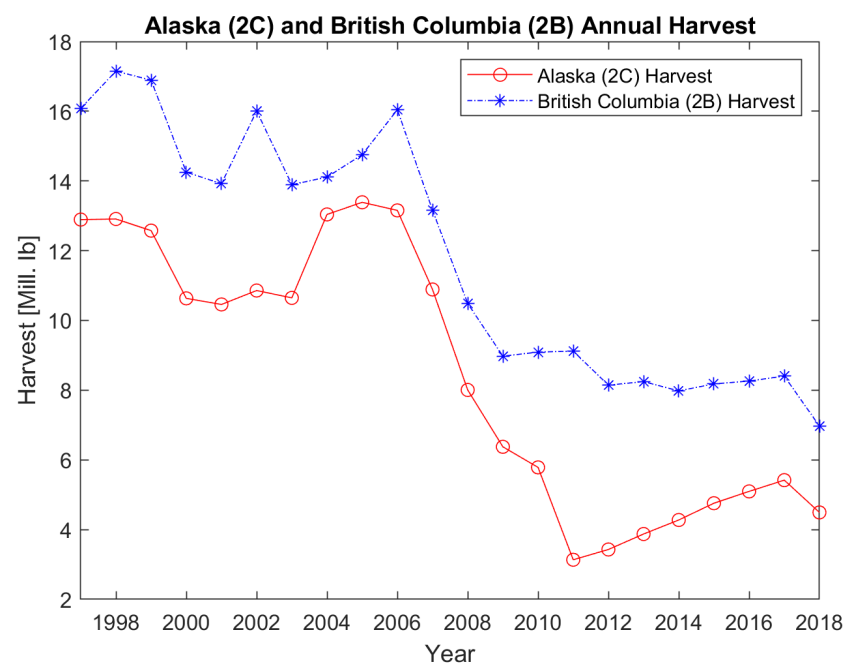

Figure 4: Harvesting of the South Alaska zone (2C) and the British Columbia zone (2B). Source: Department of Fisheries and Oceans of Canada (DFO) and National Oceanic and Atmospheric Administration (NOAA).

For each zone $i \in\{1,2\}$ the biomass dynamic follows the process presented in Equation (1) and Equation(4):

$$
\Delta I_{i, t+1}=\gamma_{i} I_{i, t}\left(1-\frac{I_{i, t}}{I_{i}^{\text {max }}}\right)-q_{i, t}+I_{i, t} \sigma_{i} \epsilon_{i, t+1}+I_{i, t} \phi_{i} \eta_{t+1}
$$

Therefore, for each zone we estimate:

$$
\frac{\Delta I_{i, t+1}+q_{i, t}}{I_{i, t}}=\gamma_{i}-\gamma_{i} \frac{I_{i, t}}{I_{i}^{\text {max }}}+\sigma_{i} \epsilon_{i, t+1}+\phi_{i} \eta_{t+1}
$$

where $\epsilon_{i, t+1}$ is an idiosyncratic biomass shock affecting area $i$, while $\eta_{t+1}$ is an aggregate shock that affects all zones simultaneously. Both shocks are assumed to be independent standard normal.

To estimate, we define the full shock for zone $i$ as $\kappa_{i, t+1}$ a normally distributed random shock, so Equation (16) can be re-written as:

$$
\frac{\Delta I_{i, t+1}+q_{i, t}}{I_{i, t}}=\gamma_{i}-\gamma_{i} \frac{I_{i, t}}{I_{i}^{\max }}+\omega_{i} \kappa_{i, t+1}
$$

Since in the regression presented in Equation (17) the shocks to the biomass in each zone may be correlated, we estimate both areas simultaneously using seemingly unrelated regressions (SUR). 
Table 1: Estimated Parameters for the Symmetric Case Halibut Biomass Dynamics In this table, we estimate the biomass dynamics parameters for the Alaska zone (2C) and the British Columbia zone (2B). The parameters are estimated using seemingly unrelated regressions (SUR). Data covers from 1996 to 2018. It is obtained from Stewart and Hicks (2017), Stewart and Webster (2017), the Department of Fisheries and Oceans of Canada (DFO) website: http://www.dfo-mpo.gc.ca and the National Oceanic and Atmospheric Administration (NOAA) website : foss.nmfs.noaa.gov. All coefficients are estimated simultaneously.

\begin{tabular}{cc} 
Panel A: Parameters for & Alaska $(2 \mathrm{C})$ Biomass \\
\hline$\gamma_{i}$ & 0.45 \\
(z-stat) & 5.43 \\
$I_{i}^{\text {max }}$ & 97.03 \\
(z-stat) & 4.18 \\
\hline$R^{2}$ & 0.41 \\
\hline
\end{tabular}

Panel B: Parameters for British Columbia (2B) Biomass

\begin{tabular}{cc}
\hline$\gamma_{i}$ & 0.79 \\
(z-stat) & 6.28 \\
$I_{i}^{\text {max }}$ & 83.78 \\
$(\mathrm{z}$-stat $)$ & 4.96 \\
\hline$R^{2}$ & 0.48 \\
\hline
\end{tabular}

Panel C: Random Shocks Parameters

\begin{tabular}{cc}
\hline$\omega_{B C}$ & 0.11 \\
$\omega_{A K}$ & 0.10 \\
$\rho$ & 0.55 \\
\hline
\end{tabular}

Table 1 shows that although the zones are similar, their biomass dynamics are different. In particular, the intrinsic growth rate $\gamma_{i}$ is statistically significant for both zones but larger for British Columbia. This parameter reflects specific characteristics of the zone's biomass that affect the expected biomass growth rate, as biological or economic factors. Figure 5 shows the logistic growth rate of the biomass for the two considered zones, South Alaska and British Columbia. For the estimated parameters, British Columbia has a greater expected biomass growth rate for most biomass levels, which will have implications for the optimal harvest in each one of the zones. 


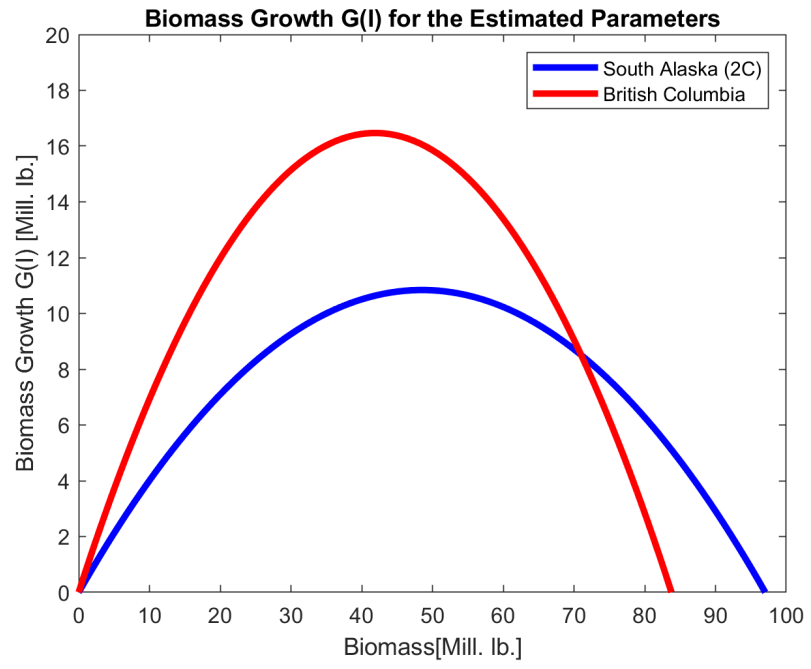

Figure 5: Logistic biomass growth rate for the South Alaska zone (2C) and the British Columbia zone (2B). Source: Based on Estimated Parameters.

To test the significance of the correlation between the shocks to the biomass of each zone, we perform a Breusch-Pagan test of independence. For the Symmetric Case, the $\chi^{2}$ statistic is 6.32 , with a p-value of 0.01 , consequently, for this case, the correlation is positive and statistically significant.

Figure 6 shows the estimated left-hand-side of the regression specified in Equation (17) versus the data:
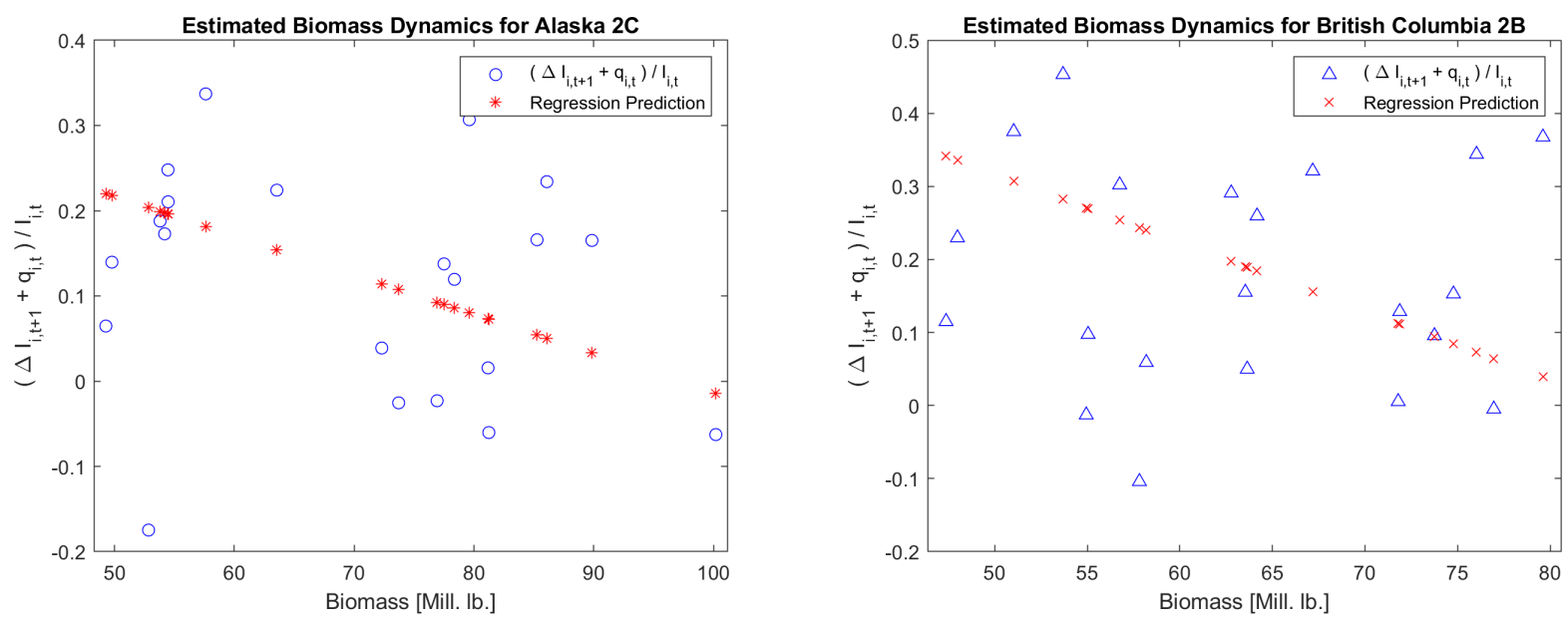

Figure 6: Estimated Biomass Dynamics for the South Alaska zone (2C) and the British Columbia zone (2B). Source: Own Elaboration Based on the Estimated Parameters.

From the estimated parameters, we can disentangle the volatility of the unexpected shocks to each zone into the volatility of the idiosyncratic shocks and the aggregate shocks. Since we have estimated three shock parameters and we have four biomass shock parameters to compute, we need to make an additional assumption. In particular, we assume that $\phi_{i}=$ $\phi \forall i \in\{1,2\}$. 
First, the variance of the estimated shocks is:

$$
\operatorname{Var}\left(\omega_{i} \kappa_{i, t+1}\right)=\operatorname{Var}\left(\sigma_{i} \epsilon_{i, t+1}+\phi \eta_{t+1}\right)
$$

therefore:

$$
\omega_{i}^{2}=\sigma_{i}^{2}+\phi^{2}
$$

Second, the covariance of the estimated shocks in different zones $i \in\{1,2\}$ is:

$$
\operatorname{Cov}\left(\omega_{1} \kappa_{1, t+1}, \omega_{2} \kappa_{2, t+1}\right)=\operatorname{Cov}\left(\sigma_{1} \epsilon_{1, t+1}+\phi \eta_{t+1}, \sigma_{2} \epsilon_{2, t+1}+\phi \eta_{t+1}\right)
$$

then:

$$
\omega_{1} \omega_{2} \rho=\phi^{2}
$$

Combining Equations (18) and Equations (19) we can solve for $\left\{\sigma_{1}, \sigma_{2}, \phi\right\}$ :

$$
\begin{aligned}
& \sigma_{1}=\sqrt{\omega_{1}^{2}-\omega_{1} \omega_{2} \rho} \\
& \sigma_{2}=\sqrt{\omega_{2}^{2}-\omega_{1} \omega_{2} \rho} \\
& \phi=\sqrt{\omega_{1} \omega_{2} \rho}
\end{aligned}
$$

Using Equation (20) and the results presented in Tables 1, we can calculate the biomass shocks parameters. These parameters are presented in Table 2.

Table 2: Estimated Parameters for Biomass Shocks, Symmetric Case

Parameters calculated from the results of the seemingly unrelated regression presented in Table 1 and the results shown in Equation (20). $\sigma_{A K}$ is the idiosyncratic volatility estimated for the Alaska zone (2C) and $\sigma_{B C}$ is the idiosyncratic volatility estimated for the British Columbia zone (2B). $\phi$ is the volatility of the aggregate biomass shock.

\begin{tabular}{cc}
\multicolumn{2}{c}{ Random Shocks Parameters } \\
\hline$\sigma_{A K}$ & 0.06 \\
$\sigma_{B C}$ & 0.08 \\
$\phi$ & 0.08 \\
\hline
\end{tabular}

\subsubsection{South Alaska (2C) and British Columbia (2B) Halibut Price Dynamics Parameters}

As shown in Equation (9), the price is modeled as a function of the aggregate harvest sold in the global market, which is represented by an inverse demand function. We use halibut prices of Alaska and British Columbia, and their aggregate harvest to identify the price parameters.

To make both prices comparable we express all of them in 2018 U.S. dollars. For the Halibut prices in British Columbia, we use the price in Canadian dollars, then we convert 
them into U.S. dollars using the corresponding year's exchange rate, and the Alaska price and the British Columbia converted prices are inflated using the U.S. CPI.

Using the size of the harvest in each zone as the weight, we calculate the weighted average price. We use it for the estimation of the price dynamics. This price and the aggregate harvest of the two zones are shown in Figure 䣕
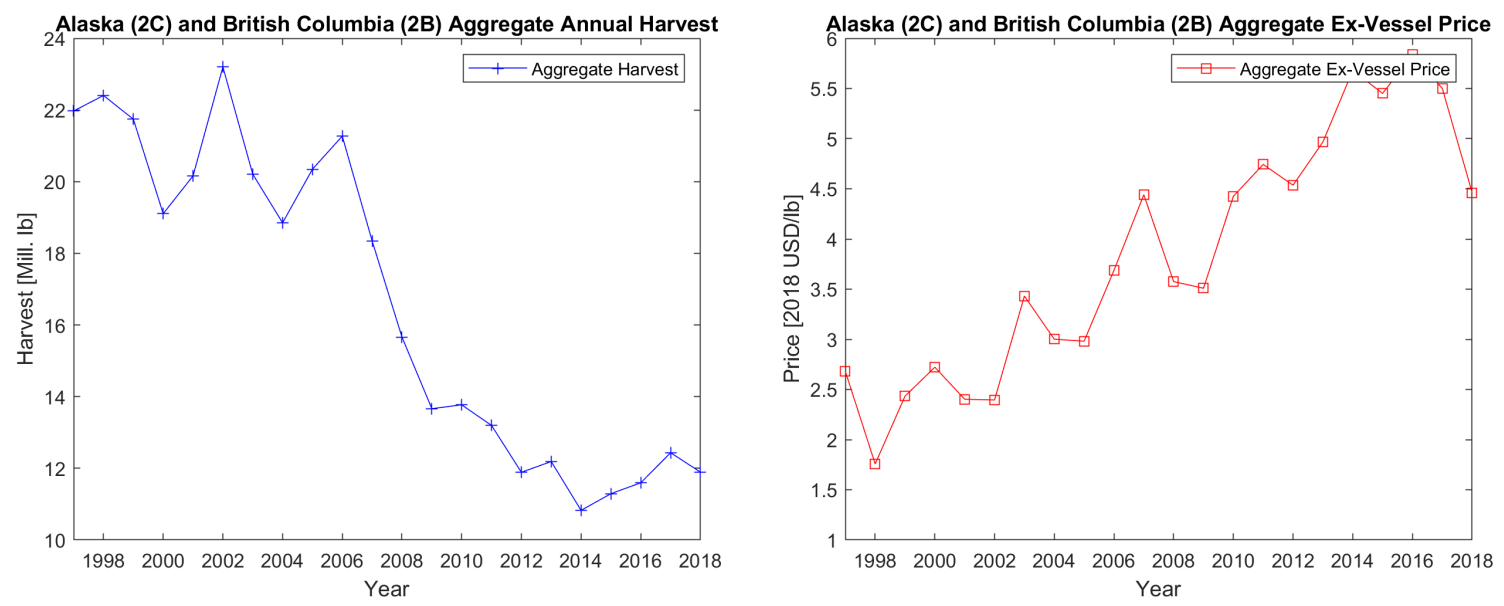

Figure 7: South Alaska (2C) and British Columbia (2B) Aggregate Ex-Vessel Real Price (2018 U.S. Dollars) and Harvest, 1996 to 2018. Source: Department of Fisheries and Oceans of Canada (DFO) and National Oceanic and Atmospheric Administration (NOAA).

Combining Equation (9) and Equation (10), we can re-write the the price dynamics as:

$$
\Delta \ln P_{t}=-\kappa \Delta \ln Q_{t}+\Delta \ln X_{t}=-\kappa \Delta \ln Q_{t}+\mu_{X}+\sigma_{X} \nu_{t}
$$

For the time-series presented in Figure 7 we estimate the regression presented in Equation (21) to obtain the parameters of the price dynamics.

Table 3: Estimated Parameters for the Halibut Price Dynamics, Symmetric Case

The parameters are estimated using maximum likelihood. We estimated the mean and volatility obtained for the estimation of an ARIMA(0,1,0) model for the Logarithm of the Halibut Ex-Vessel Price of South Alaska (2C) and British Columbia (2B). Data covers from 1996 to 2018 and is obtained from the Department of Fisheries and Oceans of Canada (DFO) website and the National Oceanic and Atmospheric Administration (NOAA) website.

\begin{tabular}{cc} 
Price Dynamics & Parameters \\
\hline$\kappa$ & 0.38 \\
(z-stat) & 0.77 \\
$\mu_{X}$ & 0.02 \\
(z-stat) & 0.40 \\
$\sigma_{X}$ & 0.17 \\
(z-stat) & 6.80 \\
\hline
\end{tabular}

\footnotetext{
${ }^{6}$ It should be noted that the prices for halibut in both zones were very similar, consistent with the idea that there is one aggregate market for the product.
} 
Figure 8 compares the estimated price with the data:

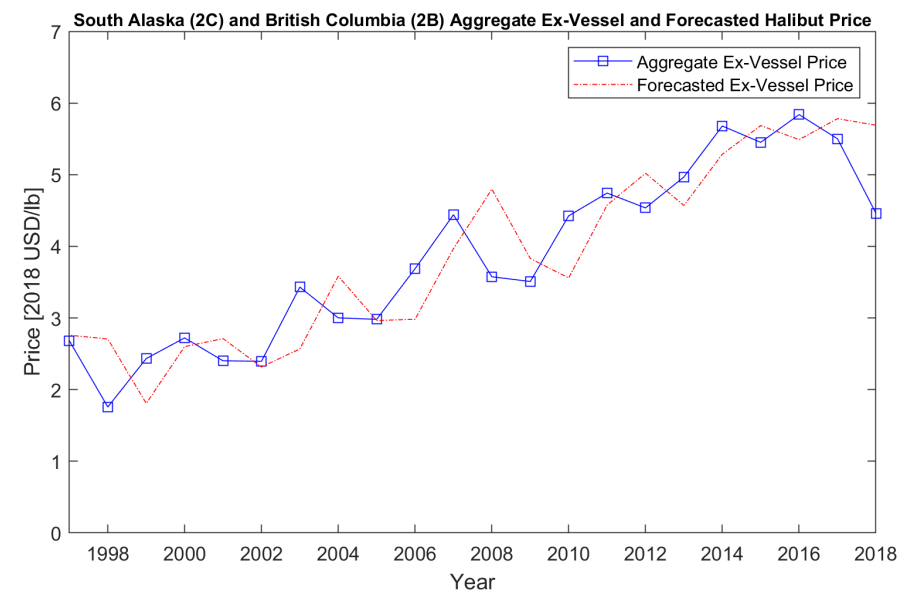

Figure 8: South Alaska (2C) and British Columbia (2B) Aggregate Ex-Vessel Real Price and Model Forecasted Price, 1996 to 2018. Source: Own Elaboration Based on the Estimated Parameters.

\subsubsection{South Alaska (2C) and British Columbia (2B) Halibut Fishery Costs Pa- rameters}

The estimation of the model's cost function, as presented in Equation (13), is one of the main challenges of the parameter estimation, as time series of harvesting costs are not available for the studied zones.

To our knowledge, few sources of real cost data are available for the studied fisheries. We focus on two surveys performed by Nelson Bros Fisheries Ltd. for the Department of Fisheries and Oceans of Canada (DFO) (Nelson (2009) and Nelson (2011)). These surveys include an estimation of the operating income for vessels harvesting halibut in British Columbia.

From these surveys, we notice that in the two years available the fixed costs constitute approximately $10 \%$ of the annual revenue, while the annual profit is approximately $20 \%$ of the annual revenue. We use these ratios to extrapolate the fixed and variables cost for each one of the studied zones. Using the available price and harvesting data, we calculate the annual revenue for each zone and construct a time series of fixed costs as:

$$
F_{t}^{i}=10 \% \times P_{t}^{i} \times q_{t}^{i}
$$

Then, we estimate the fixed cost parameter for zone $i$ as the average for the time series, rounded down to the nearest dollar:

$$
c_{0}^{i}=\left\lfloor\frac{1}{T} \sum_{t=1}^{T} F_{t}^{i}\right\rfloor
$$


After the fixed cost is estimated, we estimate the variable cost as:

$$
C_{t}^{i}=80 \% \times P_{t}^{i} \times q_{t}^{i}-c_{0}^{i}
$$

The variable cost parameter for zone $i$ is calculated as the average of the estimated variable cost divided by the annual harvest:

$$
c_{1}^{i}=\frac{1}{T} \sum_{t=1}^{T} \frac{C_{t}^{i}}{q_{t}}
$$

The estimated cost parameters are presented in Table 4

Table 4: Estimated Parameters for the Cost Function, Symmetric Case

The parameters are estimated using the assumption that the fixed costs constitute approximately $10 \%$ of the annual revenue, while the annual profit is approximately $20 \%$ of the annual revenue. The fixed cost parameter for zone $i$ is the average for the time series rounded down to the nearest dollar. The variable cost parameter for zone $i$ is calculated as the average of the estimated variable cost divided by the annual harvest.

\begin{tabular}{ccc} 
Parameter & South Alaska (2C) & British Columbia (2B) \\
\hline$c_{0}$ & 1.50 & 4.00 \\
$c_{1}$ & 2.52 & 2.76 \\
\hline
\end{tabular}

\subsection{Asymmetric Case: Alaska and British Columbia}

For the asymmetric case, we consider two zones of very different sizes: the whole of Alaska (zone 2C, 3 and 4) and the much smaller British Columbia zone (2B).

\subsubsection{Alaska (2C, 3 and 4) and British Columbia (2B) Halibut Biomass Dynam- ics Parameters}

As in the symmetric case, we use the biomass assessments provided by Stewart and Hicks (2017) and Stewart and Webster (2017). As mentioned, we consider the Alaska zone (zone 2C, 3A, 3B, and 4) and the British Columbia zone (2B), the biomass of each zone are presented in Panel A Figure 9. Panel B shows the share of each zone in the total biomass. 

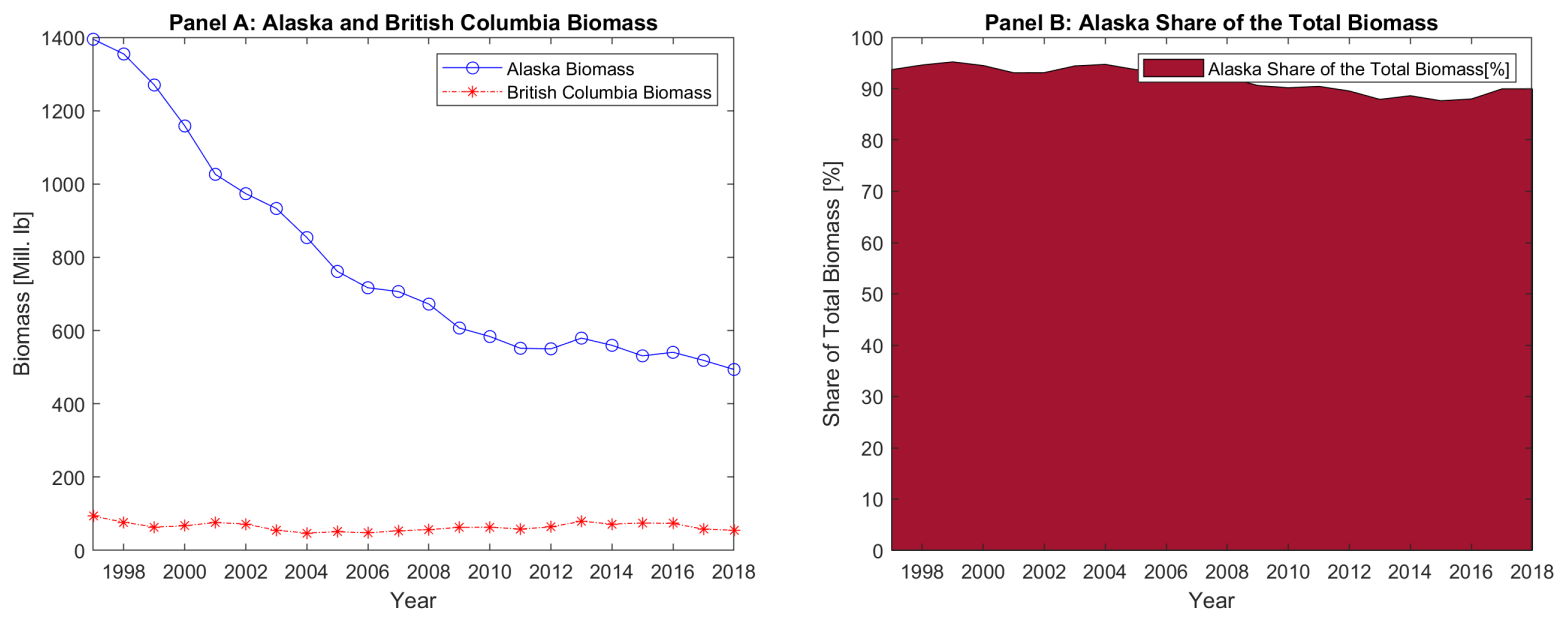

Figure 9: Biomass of the Alaska zone (2C, 3A, 3B and 4) and the British Columbia zone (2B). Source: International Pacific Halibut Commission (IPHC).

The annual harvesting for the Alaska zone (2C, 3 and 4) and the British Columbia zone (2B) are presented in Figure 10:

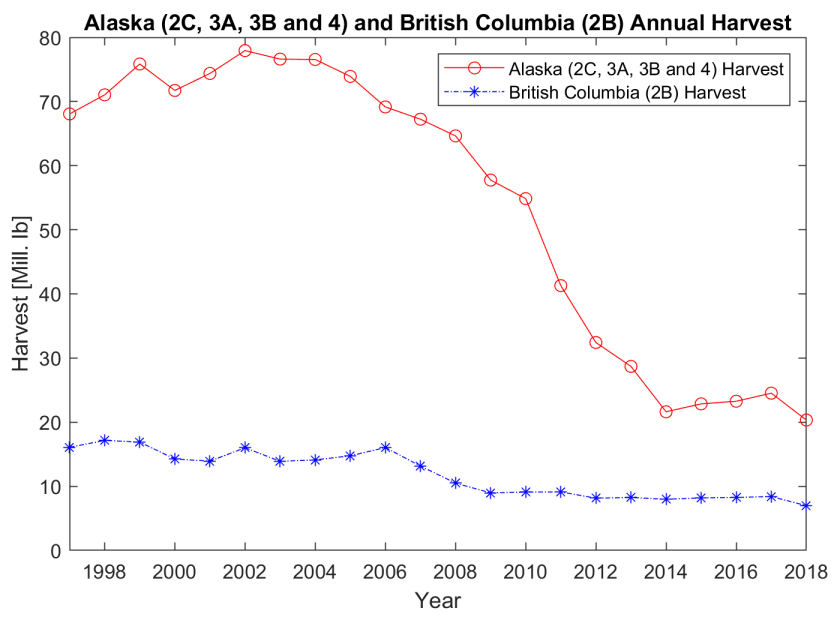

Figure 10: Harvesting of the Alaska zone (2C, 3 and 4) and the British Columbia zone (2B). Source: Department of Fisheries and Oceans of Canada (DFO) and National Oceanic and Atmospheric Administration (NOAA).

As in the symmetric case, we estimate Equation (17) for both areas simultaneously using seemingly unrelated regressions (SUR). The estimated parameters are presented in Table 5 . 
Table 5: Estimated Parameters for the Asymmetric Case Halibut Biomass Dynamics In this table, we estimate the biomass dynamics parameters for the Alaska zone $(2 \mathrm{C}, 3$ and 4$)$ and the British Columbia zone (2B). The parameters are estimated using seemingly unrelated regressions (SUR). Data covers from 1996 to 2018. It is obtained from Stewart and Hicks (2017), Stewart and Webster (2017), the Department of Fisheries and Oceans of Canada (DFO) website: http://www.dfo-mpo.gc.ca and the National Oceanic and Atmospheric Administration (NOAA) website : foss.nmfs.noaa.gov. All coefficients are estimated simultaneously.

\begin{tabular}{cc} 
Panel A: Parameters for Alaska Biomass \\
\hline$\gamma_{i}$ & 0.08 \\
$($ z-stat $)$ & 3.80 \\
$I_{i}^{\text {max }}$ & 1103.26 \\
(z-stat) & 2.94 \\
\hline$R^{2}$ & 0.22 \\
\hline
\end{tabular}

Panel B: Parameters for British Columbia Biomass

\begin{tabular}{cc}
\hline$\gamma_{i}$ & 0.77 \\
(z-stat) & 5.87 \\
$I_{i}^{\text {max }}$ & 84.22 \\
(z-stat) & 4.61 \\
\hline$R^{2}$ & 0.48 \\
\hline
\end{tabular}

Panel C: Random Shocks Parameters

\begin{tabular}{cc}
\hline$\omega_{B C}$ & 0.11 \\
$\omega_{A K}$ & 0.03 \\
$\rho$ & 0.25 \\
\hline
\end{tabular}

To test the significance of the correlation between the shocks to the biomass of each zone, we perform a Breusch-Pagan test of independence. For the Asymmetric Case, the $\chi^{2}$ statistic is 1.30 , with a p-value of 0.25 , consequently for this case although the correlation is positive, it is not statistically significant.

Figure 11 shows the estimated left-hand-side of the regression specified in Equation (17) versus the data:
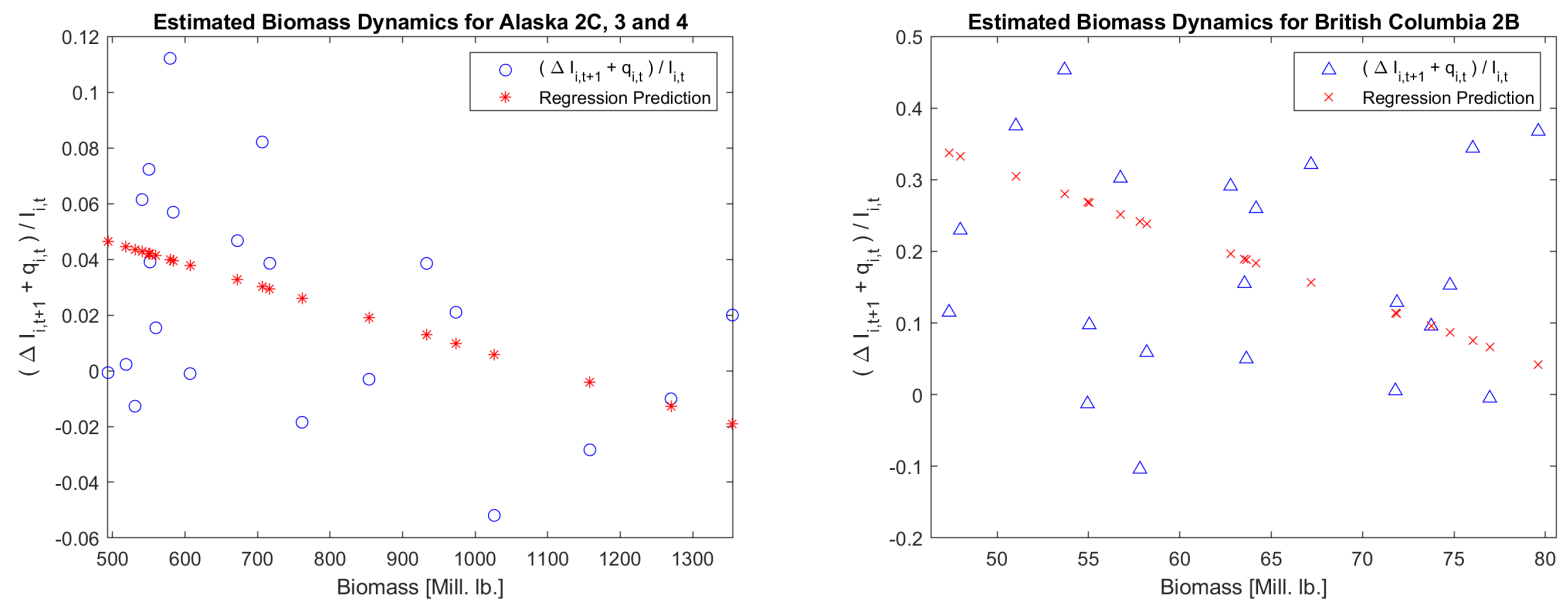

Figure 11: Estimated Biomass Dynamics for the Alaska zone (2C, 3 and 4) and the British Columbia zone (2B). Source: Own Elaboration Based on the Estimated Parameters. 
Using Equation (20) and the results presented in Table 5 , we can calculate the biomass shocks parameters. These parameters are presented in Table 6.

Table 6: Estimated Parameters for Biomass Shocks, Asymmetric Case

Parameters calculated from the results of seemingly unrelated regressions presented in Table 5 and the results shown in Equation (20). $\sigma_{A K}$ is the idiosyncratic volatility estimated for the Alaska zone $(2 \mathrm{C}, 3$ and 4$)$ and $\sigma_{B C}$ is the idiosyncratic volatility estimated for the British Columbia zone (2B). $\phi$ is the volatility of the aggregate biomass shock.

\begin{tabular}{cc}
\multicolumn{2}{l}{ Random Shocks Parameters } \\
\hline$\sigma_{A K}$ & 0.02 \\
$\sigma_{B C}$ & 0.10 \\
$\phi$ & 0.03 \\
\hline
\end{tabular}

\subsubsection{Pacific Halibut Price Dynamics Parameters}

As in the symmetric case, we use the annual harvest of each zone as the weight to calculate a unique aggregate price for this case. Figure 12 presents the aggregate price and harvest we will use to estimate the price dynamics:
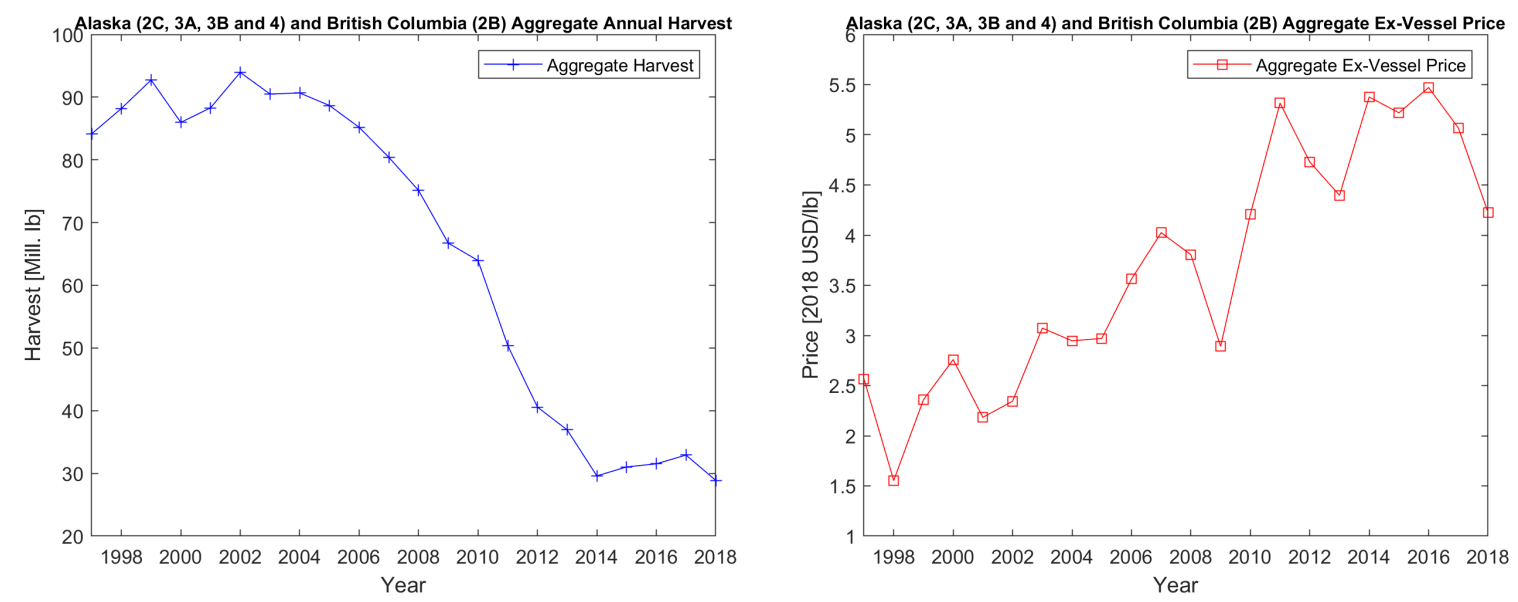

Figure 12: Alaska (2C, 3 and 4) and British Columbia (2B) Aggregate Ex-Vessel Real Price (2018 U.S. Dollars) and Harvest, 1996 to 2018. Source: Department of Fisheries and Oceans of Canada (DFO) and National Oceanic and Atmospheric Administration (NOAA).

For the time-series presented in Figure 12 we estimate the regression presented in Equation (21) to obtain the parameters of the price dynamics (Table 7). The goodness-of-fit of the estimated parameters are shown in Figure 13. 
Table 7: Estimated Parameters for the Halibut Price Dynamics, Asymmetric Case

The parameters are estimated using maximum likelihood. We estimated the mean and volatility obtained for the estimation of an ARIMA(0,1,0) model for the Logarithm of the Halibut Ex-Vessel Price of Alaska $(2 \mathrm{C}, 3$ and 4) and British Columbia (2B). Data covers from 1996 to 2018 and is obtained from the Department of Fisheries and Oceans of Canada (DFO) website and the National Oceanic and Atmospheric Administration (NOAA) website.

\begin{tabular}{|c|c|}
\hline \multicolumn{2}{|c|}{ Price Dynamics Parameters } \\
\hline$\kappa$ & 0.23 \\
\hline (z-stat) & 0.47 \\
\hline$\mu_{X}$ & 0.01 \\
\hline (z-stat) & 0.29 \\
\hline$\sigma_{X}$ & 0.21 \\
\hline (z-stat) & 6.89 \\
\hline
\end{tabular}

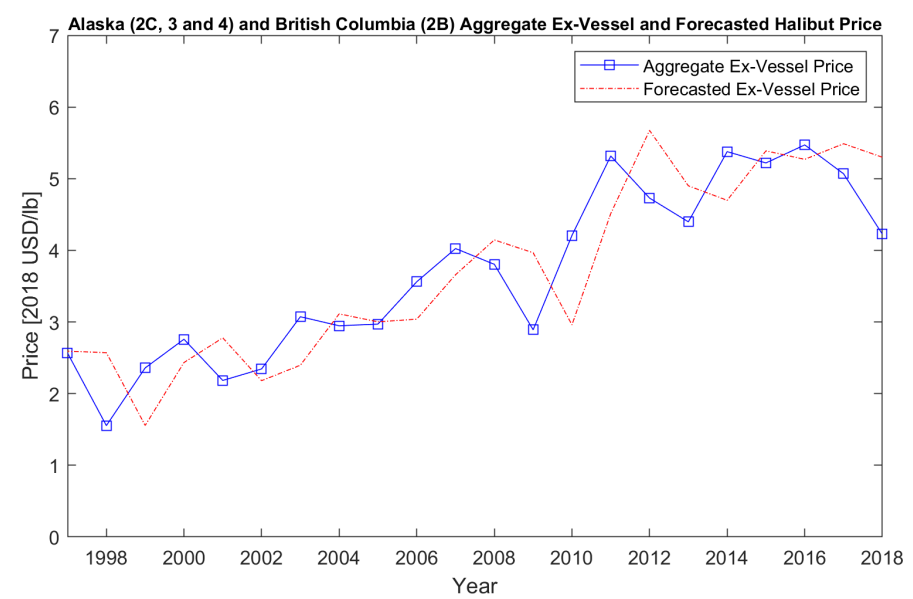

Figure 13: Alaska (2C, 3 and 4) and British Columbia (2B) Aggregate Ex-Vessel Real Price and Model Forecasted Price, 1996 to 2018. Source: Own Elaboration Based on the Estimated Parameters.

\subsubsection{Alaska (2C, 3 and 4) and British Columbia (2B) Halibut Fishery Costs Parameters}

The cost parameters for the Asymmetric Case are obtained using the same procedure discussed for the Symmetric Case. The estimated parameters are presented in Table 8 .

Table 8: Estimated Parameters for the Cost Function, Asymmetric Case

The parameters are estimated using the assumption that the fixed costs constitute approximately $10 \%$ of the annual revenue, while the annual profit is approximately $20 \%$ of the annual revenue. The fixed cost parameter for zone $i$ is the average for the time series rounded down to the nearest dollar. The variable cost parameter for zone $i$ is calculated as the average of the estimated variable cost divided by the annual harvest.

\begin{tabular}{ccc} 
Parameter & Alaska $(2 \mathrm{C}, 3$ and 4$)$ & British Columbia $(2 \mathrm{~B})$ \\
\hline$c_{0}$ & 17.00 & 4.00 \\
$c_{1}$ & 2.46 & 2.76 \\
\hline
\end{tabular}




\section{Model Results for the Pacific Halibut Fishery}

\subsection{Symmetric Case: South Alaska and British Columbia}

To illustrate the implication of the model we first consider two zones of similar size and we now solve the model for the parameters estimated in the previous section. We solve the model with the estimated parameters. We denote South Alaska (2C) "Zone 1" and British Columbia (2B) "Zone 2". The only parameter that has not been estimated is the real riskadjusted discount rate. For this parameter, we follow Pizarro and Schwartz (2021) and use a value of $2.9 \%$ for both zones.

Table 9 summarizes the parameters used for solving the model. Since the data used to estimate the required parameters is annual, we solve the model using a one-year time step. We construct the biomass, policies, and random shocks grids dividing the sets into equallyspaced discrete points. For the exogenous demand factor, we use a log-linear grid to better capture its distribution.

The biomass grid boundaries are 0.1 and carrying capacity $I^{\max }$. For the exogenous demand factor, the boundaries are the $90 \%$ confidence interval, for a 10-year time horizon, constructed using its estimated distribution. For the policy grid, the boundaries are 0.1 $1^{7}$ to 45 million pounds per year. This upper boundary ensures that the optimal harvesting is always an interior value on the constructed grid.

\footnotetext{
${ }^{7}$ Given that the inverse demand function is undefined if the harvest is zero, we choose this small as the minimum harvest.
} 
Table 9: Model Parameters for the Symmetric Case

This table summarizes the parameters estimated in Section 3. Stochastic shocks are defined to cover a $90 \%$ confidence interval.

\begin{tabular}{c|c|c|c}
\multicolumn{4}{c}{ Panel A: Grid Density } \\
Parameter & Zone 1 & Zone 2 & Description \\
\hline$n I$ & 35 & 35 & Biomass grid density \\
$n X$ & 21 & 21 & Exogenous demand factor grid density \\
$n Z$ & 5 & 5 & Biomass and demand factor shocks grid density \\
$n Q$ & 150 & 150 & Harvesting grid density \\
\hline
\end{tabular}

Panel B: Biomass Dynamics

\begin{tabular}{c|c|c|c} 
Parameter & Zone 1 & Zone 2 & Description \\
\hline$I_{i}^{\min }$ & 0.1 & 0.1 & Minimum biomass \\
$I_{i}^{\max }$ & 97.03 & 83.78 & Maximum biomass \\
$\gamma_{i}$ & 0.44 & 0.78 & Biomass intrinsic growth rate \\
$\sigma_{i}$ & 0.07 & 0.08 & Biomass idiosyncratic shock volatility \\
$\phi$ & 0.08 & 0.08 & Biomass global shock volatility \\
\hline
\end{tabular}

\begin{tabular}{c|c|c}
\multicolumn{3}{c}{ Panel C: Demand Dynamics } \\
Parameter & Value & Description \\
\hline$X_{0}$ & 11.45 & Current level of the exogenous demand factor \\
$\mu_{X}$ & 0.02 & Expected growth of the log of the exogenous demand factor \\
$\sigma_{X}$ & 0.17 & Log of the exogenous demand factor shocks volatility \\
$\kappa$ & 0.38 & Inverse demand slope \\
\hline
\end{tabular}

\begin{tabular}{c|c|c} 
& \multicolumn{2}{c}{ Panel D: Other Parameters } \\
Parameter & Value & Description \\
\hline$Z^{\min }$ & -1.65 & Min. value of the stochastic shocks \\
$Z^{\max }$ & 1.65 & Max. value of the stochastic shocks \\
$Q^{\min }$ & 0.10 & Min. value of the annual harvest \\
$Q_{1}^{\max }$ & 45.00 & Max. value of the annual harvest for South Alaska (2C) \\
$Q_{2}^{\max }$ & 45.00 & Max. value of the annual harvest for British Columbia (2B) \\
$r$ & 0.03 & Risk-adjusted discount rate \\
$c_{0}^{1}$ & 1.50 & Fixed harvesting cost for South Alaska (2C) \\
$c_{1}^{1}$ & 2.52 & Variable harvesting cost South Alaska (2C) \\
$c_{0}^{2}$ & 4.00 & Fixed harvesting cost for British Columbia (2B) \\
$c_{1}^{2}$ & 2.76 & Variable harvesting cost British Columbia (2B) \\
\hline
\end{tabular}

\subsubsection{Value Functions and Harvesting Policies. Symmetric Case}

Figure 14 shows the value of the Zone 1: South Alaska (2C) and Zone 2: British Columbia halibut fishery, for different values of the biomass in each zone, under the optimal harvesting policy, for a fixed exogenous demand factor $X_{t}=11.45 .8$

${ }^{8}$ The solution algorithm takes approximately 10 global iterations across both zones, while it takes approximately 300 iterations to fulfill the stopping criteria in each zone (absolute change of $1.0 \times 10 e^{-3}$ in the value function). The iteration errors and changes in the optimal policy converge smoothly in all global iterations. 

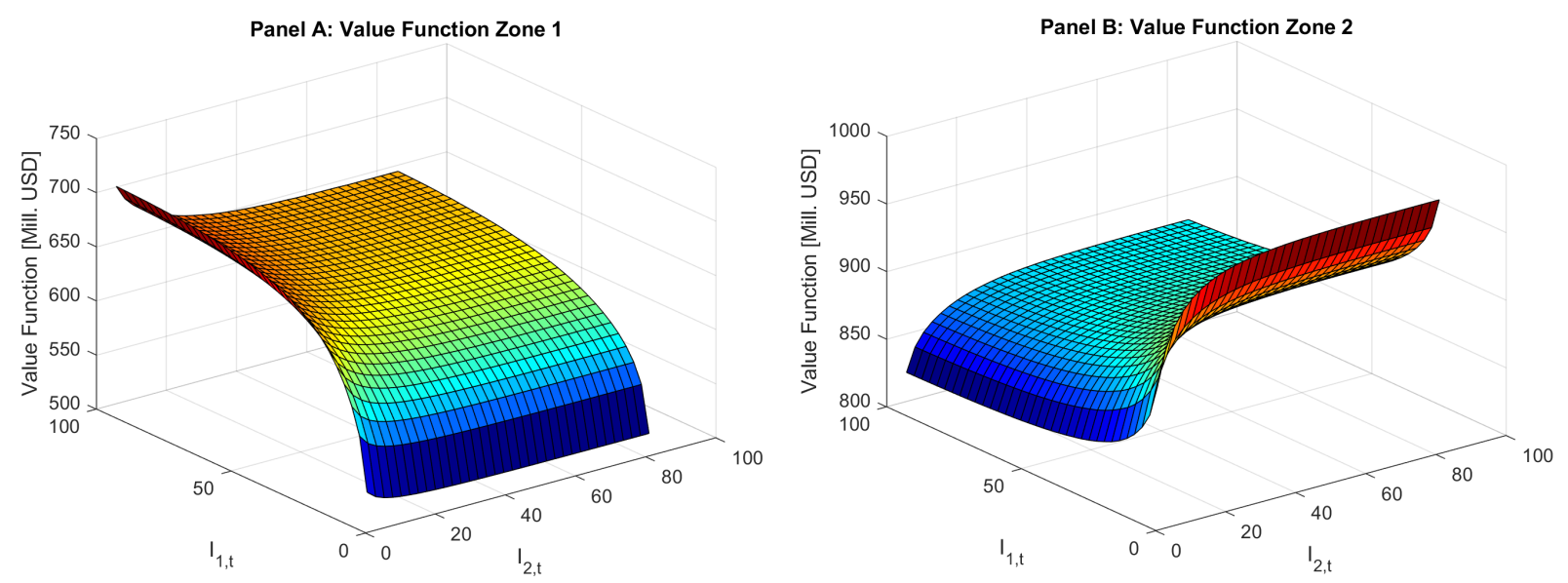

Figure 14: Zone 1: South Alaska (2C) and Zone 2: British Columbia (2B) Value Function for the Exogenous Demand $X_{t}=11.45$. Source: Own Elaboration Based on Model Results.

Figure 14 shows how the resource value is affected by the interaction between the zones. The value of the biomass in a specific zone is more valuable when the biomass is lower in the other zone, that is, the resource is more valuable when the competing zone has less biomass and consequently produces less. This can also be seen more clearly in Table 10 which shows the value in both zones for three different biomass levels in each one of the zones.

Table 10: Value of the Fishery in Zone 1 and 2 for the Symmetric Case

This table shows the value function obtained from solving the symmetric model. Zone 1: South Alaska (2C), Zone 2: British Columbia (2B). All results are computed for an exogenous demand factor of $X_{t}=11.45$.

Fishery's Value in Zone $1 V_{1, t}$ [Mill. USD] Fishery's Value in Zone $2 V_{2, t}$ [Mill. USD]

\begin{tabular}{|c|c|c|c|c|c|c|c|}
\hline$I_{t}^{1} / I_{t}^{2}$ [Mill. lb.] & 10 & 30 & 50 & $I_{t}^{1} / I_{t}^{2}$ [Mill. lb.] & 10 & 30 & 50 \\
\hline 10 & 587 & 577 & 576 & 10 & 911 & 940 & 945 \\
\hline 30 & 647 & 626 & 621 & 30 & 876 & 904 & 909 \\
\hline 50 & 667 & 644 & 638 & 50 & 864 & 889 & 893 \\
\hline
\end{tabular}

Figure 15$]$ shows the optimal harvesting for different values of the biomass in each zone. 


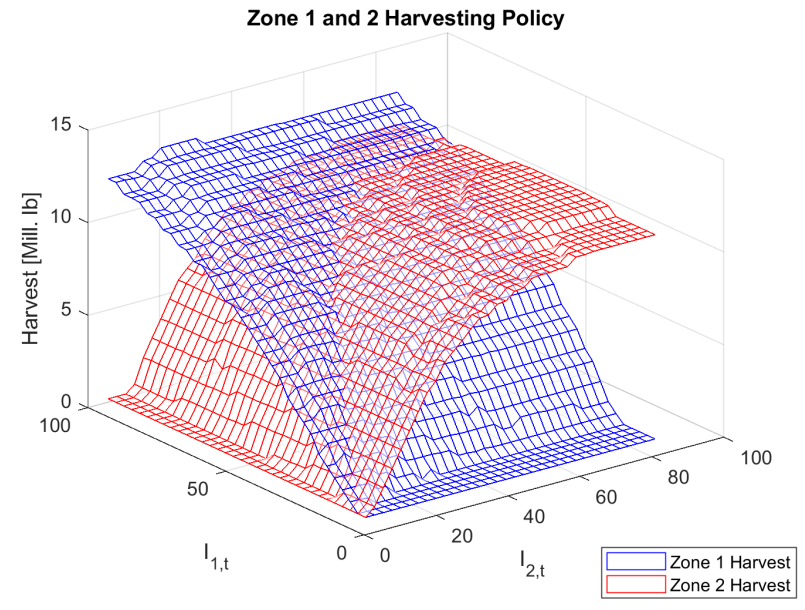

Figure 15: Zone 1: South Alaska (2C) and Zone 2: British Columbia (2B) Harvesting Policy for the Exogenous Demand $X_{t}=11.45$. Source: Own Elaboration Based on Model Results.

Figure 15 shows that the optimal annual harvest in each zone goes from values close to zero in states of low biomass to 13 million pounds per year in both zones? The lowest levels are observed only in states where the zone's biomass is almost depleted. The highest harvestings are observed in states where the biomass is high in both zones. Table 11 illustrates this effect for three different levels of biomass in each zone.

Table 11: Harvesting in Zone 1 and 2 for the Symmetric Case

This table shows the optimal harvesting policy obtained from solving the symmetric model. Zone 1: South Alaska (2C), Zone 2: British Columbia (2B). All results are computed using an exogenous demand factor of $X_{t}=11.45$.

Harvesting in Zone $1 q_{1, t}$ [Mill. lb.] Harvesting in Zone $2 q_{2, t}$ [Mill. lb.]

\begin{tabular}{c|cccc|ccc}
\multicolumn{1}{l}{$I_{t}^{1} / I_{t}^{2}$ [Mill. lb.] } & 10 & 30 & 50 & $I_{t}^{1} / I_{t}^{2}$ [Mill. lb.] & 10 & 30 & 50 \\
\cline { 2 - 6 } 10 & 0.8 & 0.5 & 0.5 & 10 & 2.5 & 8.6 & 10.6 \\
30 & 5.1 & 4.7 & 3.9 & 30 & 2.0 & 8.6 & 11.4 \\
50 & 8.6 & 8.4 & 7.9 & 50 & 1.4 & 8.4 & 11.0
\end{tabular}

Figure 16 shows the aggregate harvesting for both zones.

\footnotetext{
${ }^{9}$ The harvesting policy upper-bound was set at 45 million pounds per year in each zone. This limit is not binding.
} 


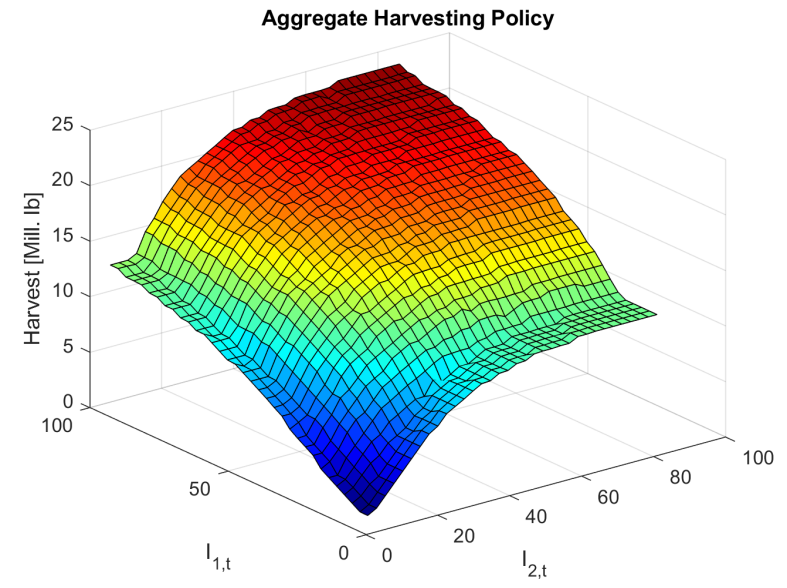

Figure 16: Aggregate Harvesting Policy for the Exogenous Demand $X_{t}=11.45$. Symmetric Case. Source: Own Elaboration Based on Model Results.

Figure 16 shows that the aggregate annual optimal harvesting goes from values close to zero to 24 million pounds per year in states of high biomass in both zones. This figure helps us illustrate part of the interactions between both zones, in particular, that if a zone has available biomass, while the second is depleted, the total production increases, but it is still lower than in the case that both zones have high biomass. This occurs because when a zone produces without competing with the second zone, it will select a level of harvest that balances selling a higher harvest with selling at a lower price.

Recall that the global price is determined by an exogenous demand factor $X_{t}$ and the aggregate harvest of the two zones. Figure 17 shows the global market price for the aggregate harvest presented in Figure 16 for different levels of the biomass for both zones. Here we notice that the price is highest when the resource is not available in both zones, and as the biomass increases the price decreases. This is explained by the increase in the harvest in those states. Table 12 shows this for three different levels of the biomass in both zones.

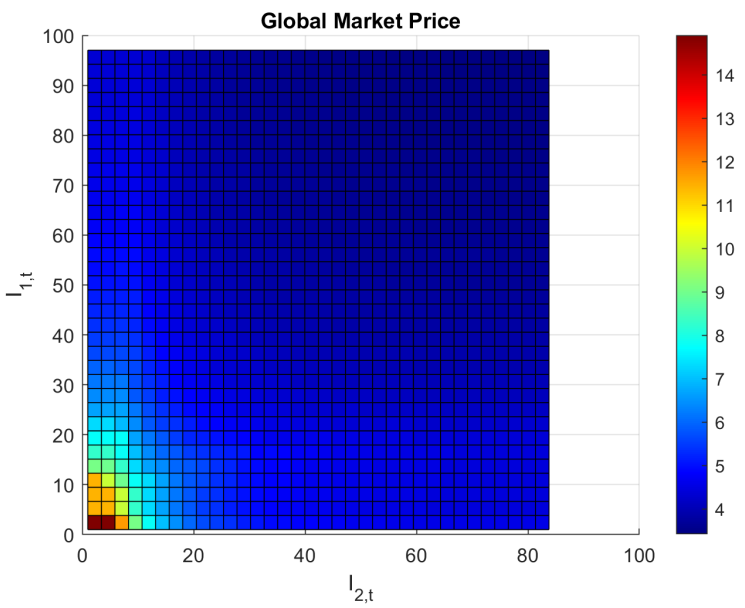

Figure 17: Global Market Price for the Exogenous Demand $X_{t}=11.45$. Symmetric Case. Source: Own Elaboration Based on Model Results. 
Table 12: Global Price for the Symmetric Case

This table shows the global price obtained from the optimal harvesting policy in each zone and the global exogenous demand factor. All results are computed for an exogenous demand factor of $X_{t}=11.45$.

Global Price: $P_{t}[\mathrm{USD} / \mathrm{lb}$.
\begin{tabular}{c|ccc}
\multicolumn{1}{c}{$I_{t}^{1} / I_{t}^{2}$ [Mill. lb.] } & 10 & 30 & 50 \\
\cline { 2 - 4 } 10 & 7.3 & 4.9 & 4.6 \\
30 & 5.4 & 4.3 & 4.1 \\
50 & 4.8 & 3.9 & 3.7
\end{tabular}

\subsubsection{Harvesting, Biomass and Price Simulations. Symmetric Case}

To study the halibut biomass and global price dynamics if the optimal harvesting policy is implemented in both zones, we generate multiple shocks for the biomass and the exogenous demand factor. With these shocks, the current state of global demand factor and the biomass, the estimated dynamics and the optimal policy, we simulate 10,000 different paths over a horizon of 10 years for the biomass, the harvest and the halibut global price. All simulations start from the current state of the exogenous demand factor $X_{0}=11.45$ and the biomass: $I_{1,0}=81.18$ million pounds in Zone 1 (South Alaska $(2 \mathrm{C})$ ) and $I_{2,0}=55.04$ million pounds in Zone 2 (British Columbia (2B)).

Figure 18 presents the median, $10^{\text {th }}$ and $90^{\text {th }}$ percentiles of the 10,000 simulated paths over a 10-year horizon for the biomass in each zone.
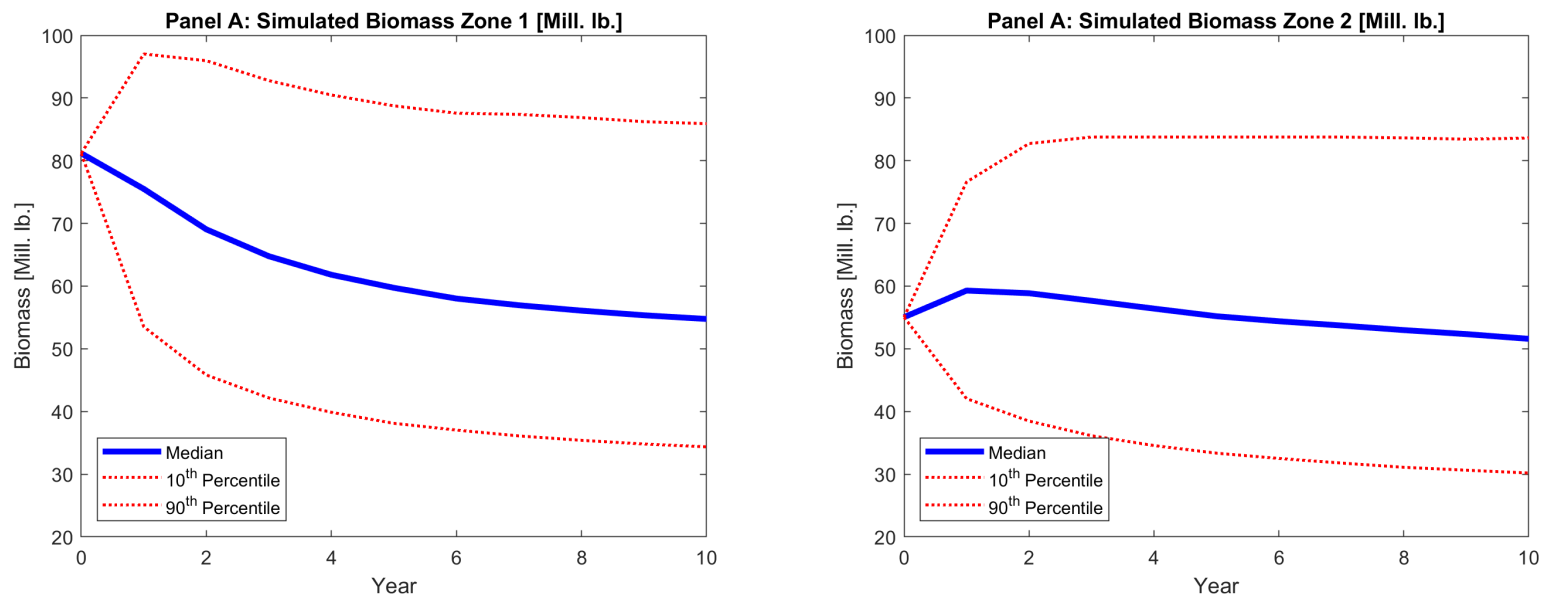

Figure 18: Zone 1: South Alaska (2C) and Zone 2: British Columbia (2B) Simulated Biomass. Source: Own Elaboration Based on Model Simulations.

Panel A of Figure 18 shows that the biomass is expected to decrease in Zone 1: South Alaska (2C), while Panel B shows that the biomass is expected to slightly decrease in Zone 2: British Columbia (2B). This figure also shows the biomass remains away from depletion with $90 \%$ probability. The $90^{t h}$ percent percentile shows that in paths of biomass growth will approach its carrying capacity $\left(I^{\max }\right)$. 
Figure 19 presents the median, $10^{\text {th }}$ and $90^{\text {th }}$ percentiles of the simulated harvesting in each zone.
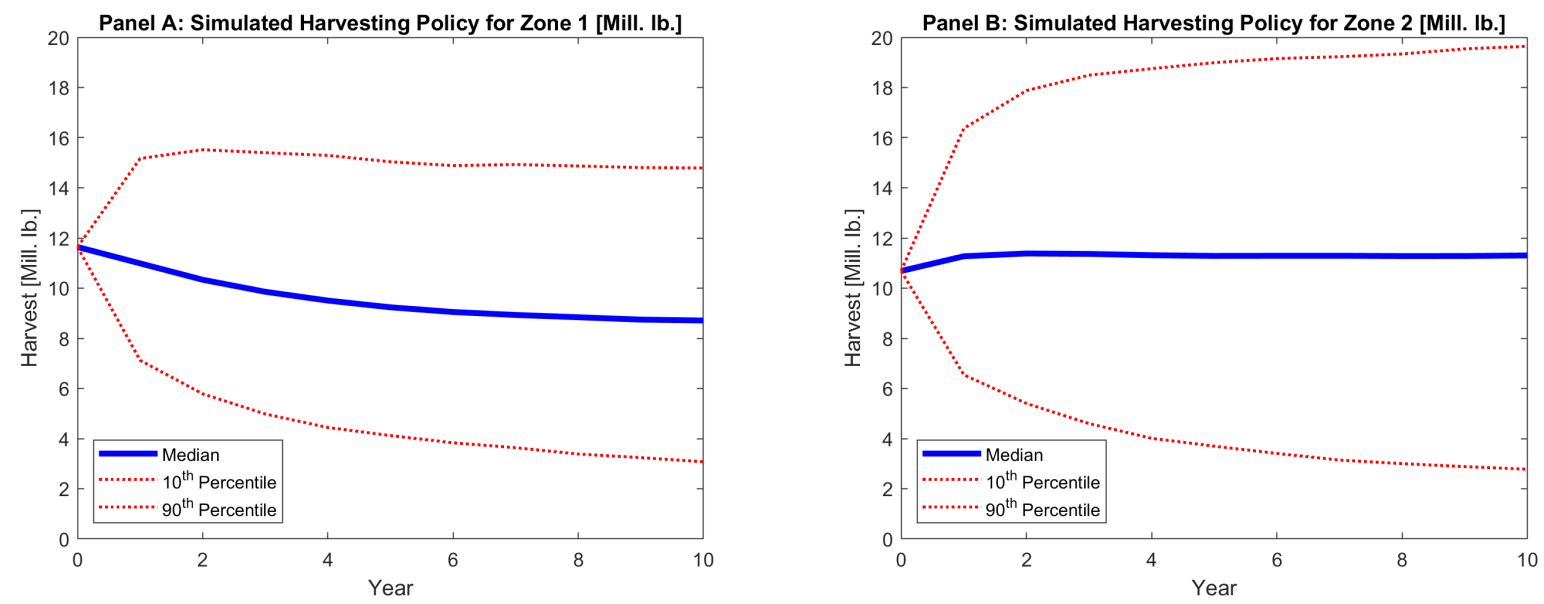

Figure 19: Zone 1: South Alaska (2C) and Zone 2: British Columbia (2B) Simulated Harvesting. Source: Own Elaboration Based on Model Simulations.

Panel A of Figure 19 shows the simulated harvesting in Zone 1: South Alaska (2C), Panel $\mathrm{B}$ shows the simulated harvest in Zone 2: British Columbia (2B). The figures show the median harvest in British Columbia (2B) increases over the simulated period, whereas the median harvest decreases in South Alaska (2C). As both zones face similar global uncertainty, this is, global biomass and exogenous demand factor shocks, these differences are mostly driven by the differences in the biomass dynamics. As shown in Figure 5, the expected biomass growth is greater, for most biomass levels, in British Columbia, this faster growth increases the incentives to harvest today, as the resource will recover faster in the following periods, in comparison to South Alaska.

Figure 20 presents the median, $10^{\text {th }}$ and $90^{\text {th }}$ percentiles of the simulated aggregate harvesting and global price.
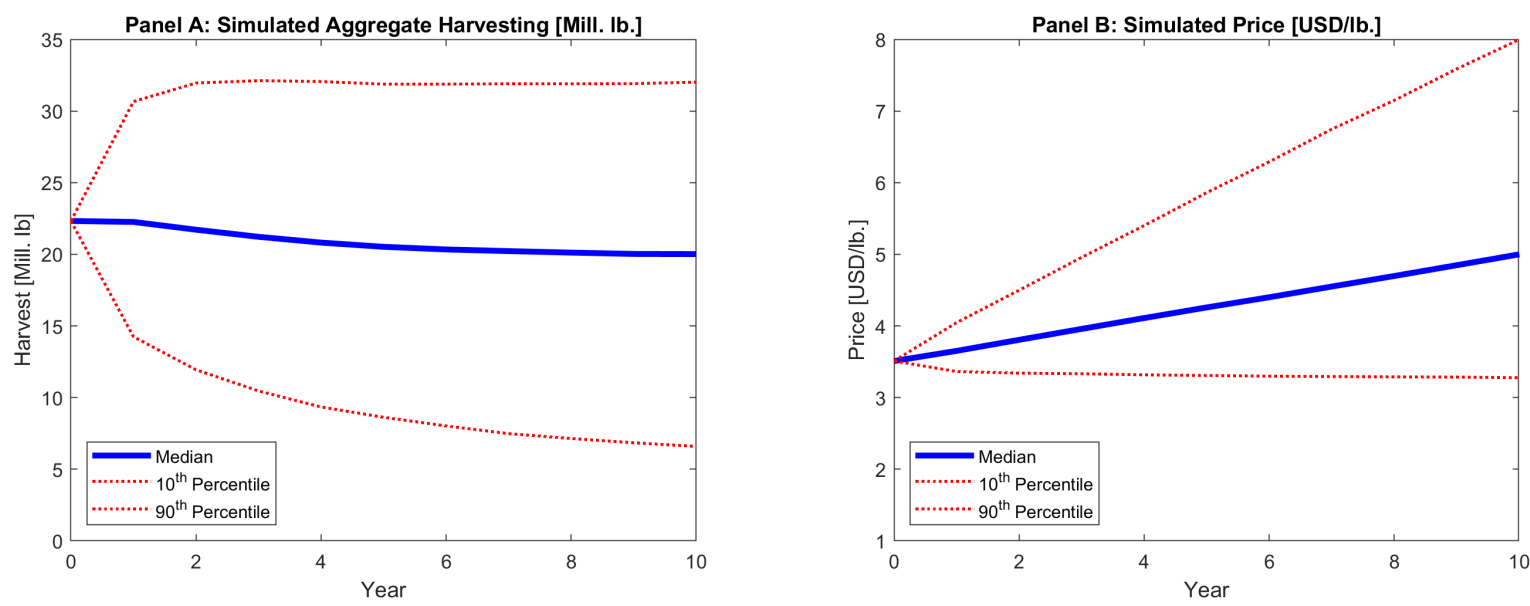

Figure 20: Zone 1: South Alaska (2C) and Zone 2: British Columbia (2B) Simulated Aggregate Harvest and Global Market Price. Source: Own Elaboration Based on Model Simulations. 
Panel A of Figure 20 shows that the global harvesting is expected to decrease over time, it will not be less than 5 million pounds with $90 \%$ probability, while it may be slightly higher than 30 million pounds per year. Panel B shows the global price. Overall, the price is expected to increase, while presenting an asymmetric distribution. The increase in the price is related to the expected growth in the demand factor and the decrease in the harvesting. This occurs because there is a limit to the benefits of harvesting due to the negative slope of the demand function, therefore, the fisheries will not harvest excessively high quantities, as this policy will push the price down, reducing their revenues. On the other hand, simulated high prices are related to low biomass states in both zones.

\subsection{Asymmetric Case: Alaska and British Columbia}

We now consider two zones of significantly different sizes and solve the model with the parameters estimated in Section 3 for the Asymmetric Case. We denote Alaska (2C, 3 and 4) "Zone 1" and British Columbia (2B) "Zone 2". As in the Symmetric Case, we use a real risk-adjusted discount rate of $2.9 \%$ for both zones.

Table 13 summarizes the parameters used for solving the model. We follow the grid construction procedure for most of the required grids, except for the policy grid in Alaska. For this zone, the policy grid boundaries are $0.11^{10}$ to 250 million pounds per year. This upper boundary ensures that the optimal harvesting is always an interior value on the constructed grid for this larger zone.

\footnotetext{
${ }^{10}$ Given that the inverse demand function is undefined if the harvest is zero, we choose this small as the minimum harvest.
} 
Table 13: Model Parameters for the Asymmetric Case

This table summarizes the parameters estimated in Section 3. Stochastic shocks are defined to cover a $90 \%$ confidence interval.

\begin{tabular}{c|c|c|c}
\multicolumn{4}{c}{ Panel A: Grid Density } \\
Parameter & Zone 1 & Zone 2 & Description \\
\hline$n I$ & 35 & 35 & Biomass grid density \\
$n X$ & 21 & 21 & Exogenous demand factor grid density \\
$n Z$ & 5 & 5 & Biomass and demand factor shocks grid density \\
$n Q$ & 150 & 150 & Harvesting grid density \\
\hline
\end{tabular}

Panel B: Biomass Dynamics

\begin{tabular}{c|c|c|c} 
Parameter & Zone 1 & Zone 2 & Description \\
\hline$I_{i}^{\min }$ & 0.1 & 0.1 & Minimum biomass \\
$I_{i}^{\max }$ & $1,146.37$ & 84.22 & Maximum biomass \\
$\gamma_{i}$ & 0.08 & 0.77 & Biomass intrinsic growth rate \\
$\sigma_{i}$ & 0.02 & 0.08 & Biomass idiosyncratic shock volatility \\
$\phi$ & 0.03 & 0.03 & Biomass global shock volatility \\
\hline
\end{tabular}

Panel C: Demand Dynamics

\begin{tabular}{c|c|c} 
Parameter & Value & Panel C: Demand Dynamics \\
\hline$X_{0}$ & 9.41 & Current level of the exogenous demand factor \\
$\mu_{X}$ & 0.01 & Expected growth of the log of the exogenous demand factor \\
$\sigma_{X}$ & 0.21 & Log of the exogenous demand factor shocks volatility \\
$\kappa$ & 0.24 & Inverse demand slope \\
\hline
\end{tabular}

\begin{tabular}{c|c|c} 
& \multicolumn{2}{c}{ Panel D: Other Parameters } \\
Parameter & Value & Description \\
\hline$Z^{\min }$ & -1.65 & Min. value of the stochastic shocks \\
$Z^{\max }$ & 1.65 & Max. value of the stochastic shocks \\
$Q^{\min }$ & 0.10 & Min. value of the annual harvest \\
$Q_{1}^{\max }$ & 100.00 & Max. value of the annual harvest for Alaska $(2 \mathrm{C}, 3$ and 4$)$ \\
$Q_{2}^{\max }$ & 45.00 & Max. value of the annual harvest for British Columbia $(2 \mathrm{~B})$ \\
$r$ & 0.03 & Risk-adjusted discount rate \\
$c_{0}^{1}$ & 17.00 & Fixed harvesting cost for Alaska (2C, 3 and 4$)$ \\
$c_{1}^{1}$ & 2.46 & Variable harvesting cost Alaska (2C, 3 and 4$)$ \\
$c_{0}^{2}$ & 4.00 & Fixed harvesting cost for British Columbia $(2 \mathrm{~B})$ \\
$c_{1}^{2}$ & 2.76 & Variable harvesting cost British Columbia (2B) \\
\hline
\end{tabular}

\subsubsection{Value Functions and Harvesting Policies. Asymmetric Case.}

Figure 21 shows the value of the Zone 1: Alaska (2C, 3 and 4) and Zone 2: British Columbia (2B) halibut fishery, for different values of the biomass in each zone, under the optimal harvesting policy, for a fixed exogenous demand factor $X_{t}=9.41$. 

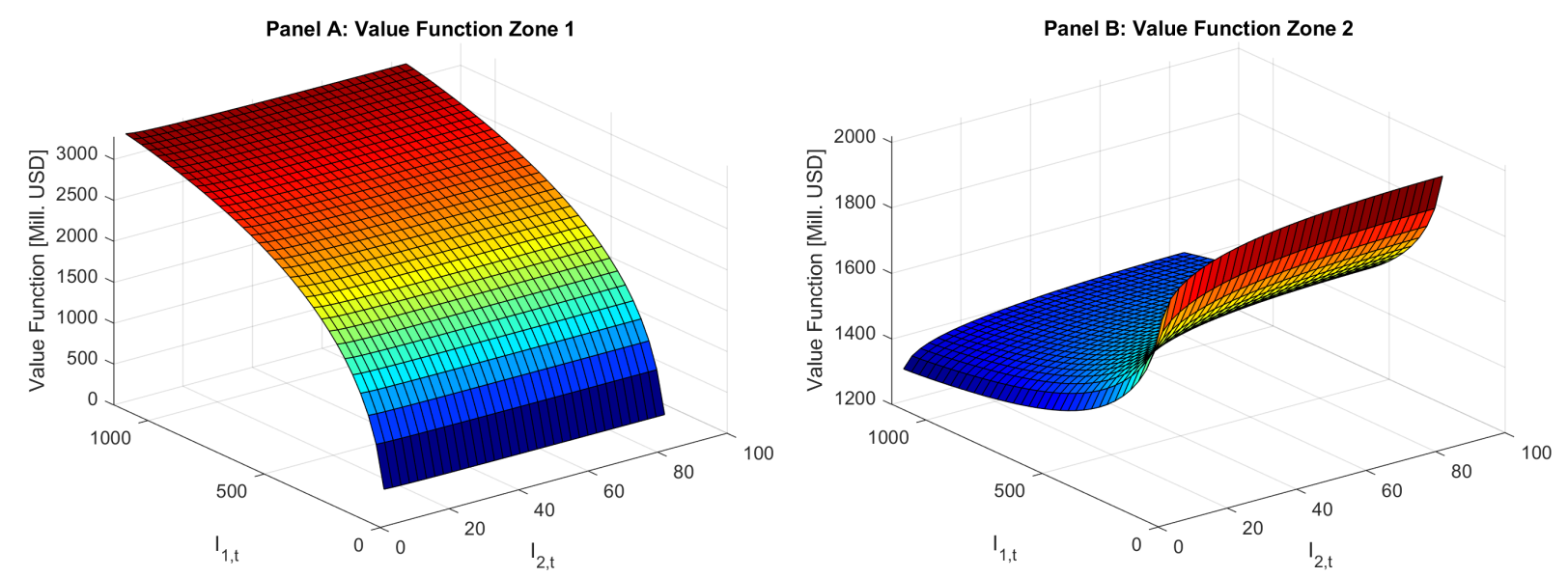

Figure 21: Zone 1: Alaska (2C, 3 and 4) and Zone 2: British Columbia (2B) Value Function for the Exogenous Demand $X_{t}=9.41$. Source: Own Elaboration Based on Model Results.

Figure 21 shows how different the interaction between the zones is in this case. The value of the larger biomass zone (Alaska) is almost not affected by the other zone, that is, the value of the resource is not affected by a significantly smaller competing zone. Therefore, this indicates that Zone 1 (Alaska) will maximize its value almost as if it was the only fishery in the market. On the other hand, the smaller zone (British Columbia) value will be affected by the biomass level of the larger zone, thus its value will fluctuate according to the biomass of the larger zone. This can also be seen in Table 14.

Table 14: Value of the Fishery in Zone 1 and 2 for the Asymmetric Case

This table shows the value function obtained from solving the asymmetric model. Zone 1: Alaska (2C, 3 and 4), Zone 2: British Columbia (2B). All results are computed for an exogenous demand factor of $X_{t}=9.41$.

Fishery's Value in Zone $1 V_{1, t}$ [Mill. USD] Fishery's Value in Zone $2 V_{2, t}$ [Mill. USD]

\begin{tabular}{|c|c|c|c|c|c|c|c|}
\hline$I_{t}^{1} / I_{t}^{2}$ [Mill. lb.] & 10 & 30 & 50 & $I_{t}^{1} / I_{t}^{2}$ [Mill. lb.] & 10 & 30 & 50 \\
\hline 100 & 1169 & 1162 & 1161 & 100 & 1736 & 1809 & 1834 \\
\hline 300 & 2076 & 2060 & 2058 & 300 & 1548 & 1621 & 1647 \\
\hline 500 & 2534 & 2511 & 2503 & 500 & 1461 & 1524 & 1550 \\
\hline
\end{tabular}

Figure 22 shows the optimal harvesting for the asymmetric model, as a function of the biomass in each zone. 


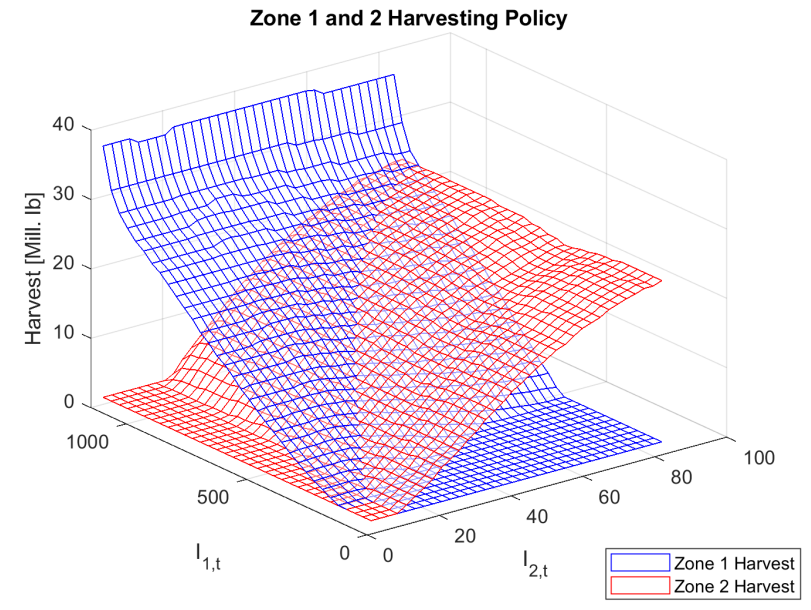

Figure 22: Zone 1: Alaska (2C, 3 and 4) and Zone 2: British Columbia (2B) Harvesting Policy for the Exogenous Demand $X_{t}=9.41$. Source: Own Elaboration Based on Model Results.

Figure 22 shows that the optimal harvesting goes from values close to zero in states of low biomass to over 40 million pounds per year in states of high biomass in Zone 1 . In Zone 2 harvest also starts at values close to zero in states of low biomass but increases to 25 million pounds per year in states of high biomass in Zone 2 and Zone 1. Table 15 complements these results for multiple levels of the biomass in each zone.

Table 15: Harvesting in Zone 1 and 2 for the Asymmetric Case

This table shows the optimal harvesting policy obtained from solving the symmetric model. Zone 1: Alaska (2C, 3 and 4), Zone 2: British Columbia (2B). All results are computed for an exogenous demand factor of $X_{t}=9.41$.

\begin{tabular}{|c|c|c|c|c|c|c|c|}
\hline \multicolumn{4}{|c|}{ Harvesting in Zone 1: $q_{1, t}$ [Mill. lb.] } & \multicolumn{4}{|c|}{ Harvesting in Zone 2: $q_{2, t}$ [Mill. lb.] } \\
\hline$I_{t}^{1} / I_{t}^{2}$ [Mill. lb.] & 10 & 30 & 50 & $I_{t}^{1} / I_{t}^{2}[$ Mill. lb.] & 10 & 30 & 50 \\
\hline 100 & 1.0 & 1.0 & 1.0 & 100 & 1.0 & 8.7 & 16.7 \\
\hline 300 & 3.7 & 1.8 & 1.0 & 300 & 1.0 & 8.3 & 16.2 \\
\hline 500 & 9.3 & 8.5 & 5.9 & 500 & 1.0 & 8.3 & 16.2 \\
\hline
\end{tabular}

Table 15 shows that although the value of the fishery in Zone 1 is not significantly affected by the biomass in Zone 2, the harvest is, especially if the biomass in Zone 1 is smal[11. In scenarios of small biomass in Zone 1, an additional unit of the resource becomes extremely valuable for the fishery, as its biomass annual growth is considerably low, particularly in comparison to Zone 2, thus enhancing the incentives to preserve the biomass and consequently increase the continuation value of the fishery.

Table 15 shows that, for Zone 2, the harvest is almost unaffected by the biomass in Zone 1 . That is an interesting feature of the model, as it points that when facing a large competitor, a fishery will act like a price-taker, focusing on the exogenous demand factor and local biomass to determine the annual harvest.

\footnotetext{
${ }^{11} I^{\max }=1,146.37$
} 
Figure 23 shows that the aggregate annual optimal harvesting goes from values close to zero to 60 million pounds per year in states of high biomass in both zones. From both policies and their combination, is possible to notice that most of the interaction is driven by the optimal harvesting policy in Zone 2. This is consistent with the notion that Zone 1 maximizes its value almost independently from Zone 2, while Zone 2 does take into account the optimal policy in Zone 1.

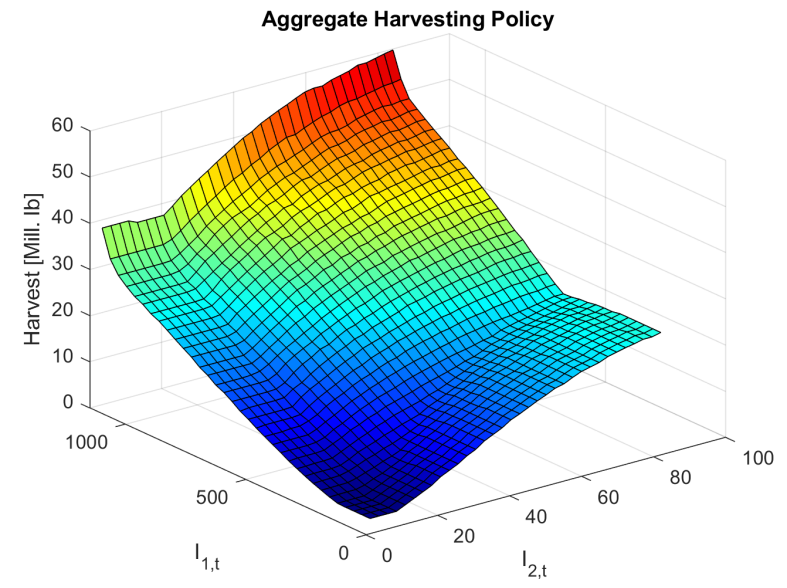

Figure 23: Aggregate Harvesting Policy for the Exogenous Demand $X_{t}=9.41$. Asymmetric Case. Source: Own Elaboration Based on Model Results.

Figure 24 shows the global market price, in the asymmetric case, for the aggregate harvest presented in Figure 23 for different levels of the biomass for both zones. Here, as in the symmetric case, we notice that the price is highest when the resource is not available in both zones and as the biomass increases the price decreases. Table 16 shows this for three different levels of the biomass in both zones.

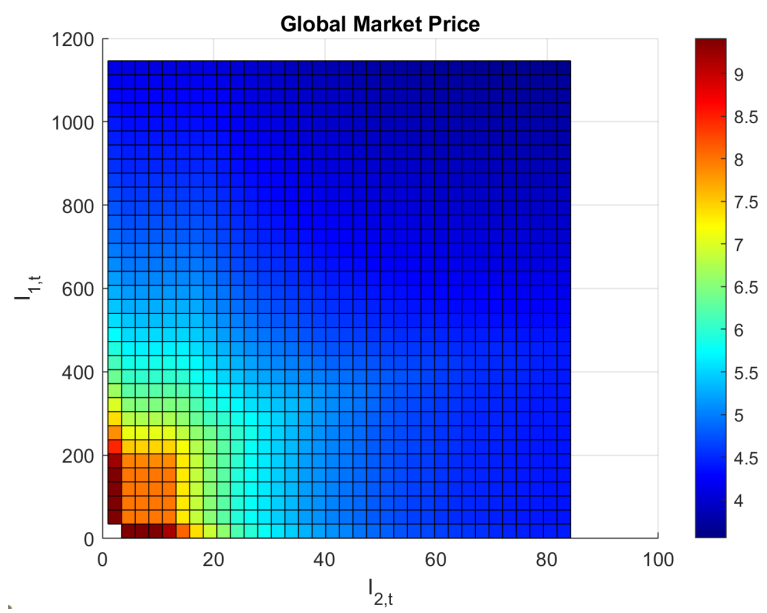

Figure 24: Global Market Price for the Exogenous Demand $X_{t}=9.41$. Asymmetric Case. Source: Own Elaboration Based on Model Results. 
Table 16: Global Price for the Asymmetric Case

This table shows the global price obtained from the optimal harvesting policy in each zone and the global exogenous demand factor, for the Asymmetric Case. All results are computed for an exogenous demand factor of $X_{t}=9.41$.

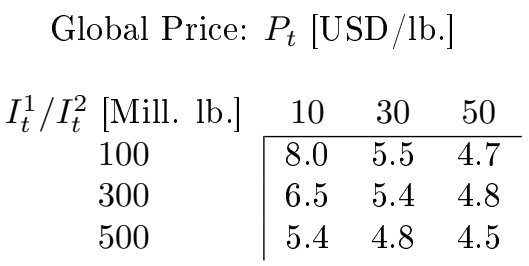

\subsubsection{Harvesting, Biomass and Price Simulations. Asymmetric Case}

As in the Symmetric Case, we simulate 10,000 different paths over a horizon of 10 years for the biomass, the harvest and the global price. All simulations start from the current state of the exogenous demand factor $X_{0}=9.41$ and biomass: $I_{1,0}=493.73$ million pounds in Zone 1 (Alaska (2C, 3 and 4)) and $I_{2,0}=55.04$ million pounds in Zone 2 (British Columbia (2B)).

Figure 25 presents the median, $10^{t h}$ and $90^{t h}$ percentile of the 10,000 simulated paths over the 10-year horizon for the biomass in each zone.
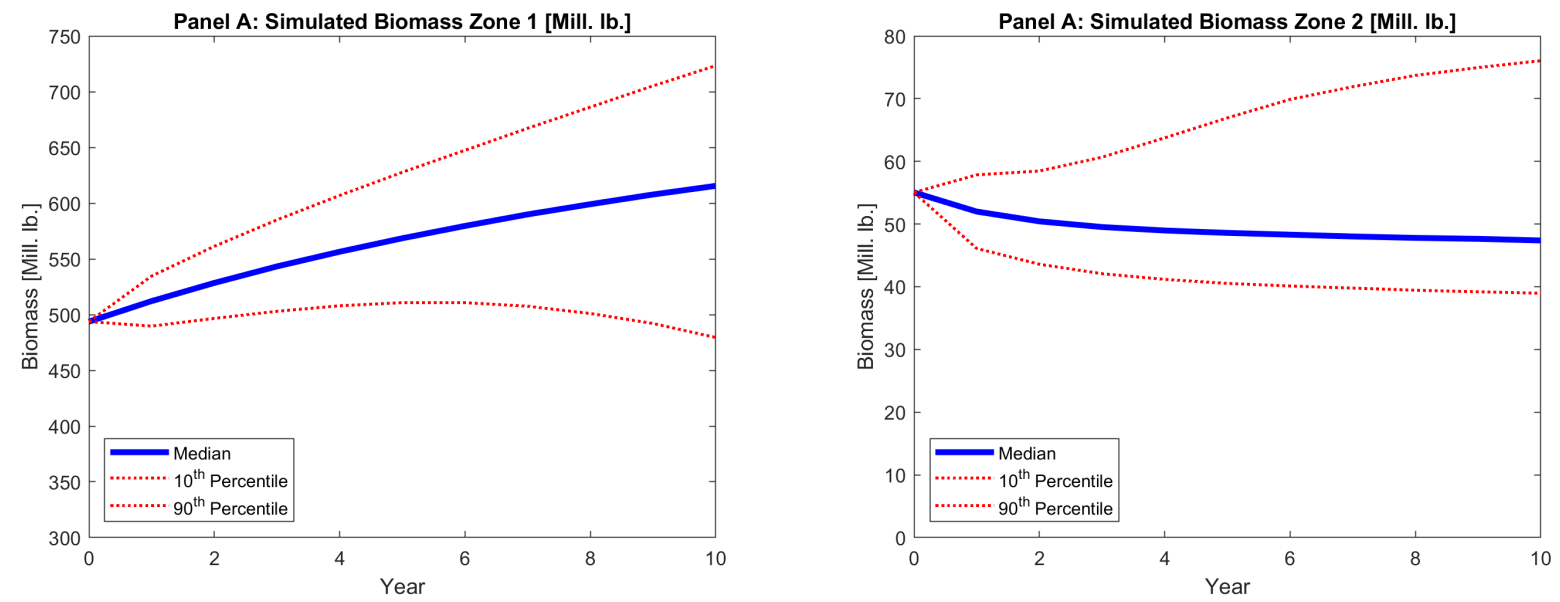

Figure 25: Zone 1: Alaska (2C, 3 and 4) and Zone 2: British Columbia (2B) Simulated Biomass. Source: Own Elaboration Based on Model Simulations.

Panel A of Figure 25 shows that the biomass is expected to increase in Zone 1: Alaska (2C, 3 and 4), while Panel B shows that the biomass is expected to decrease in Zone 2: British Columbia (2B). As in the Symmetric Case, the biomass will not approach depletion with $90 \%$ probability, but in contrast to the Symmetric Case, the $90^{\text {th }}$ percentile will not reach the carrying capacity $\left(I_{\max }\right)$ for neither zone.

Figure 26 presents the median, $10^{\text {th }}$ and $90^{\text {th }}$ percentile of the simulated paths over the 10-year horizon for the harvesting policy in each zone. 

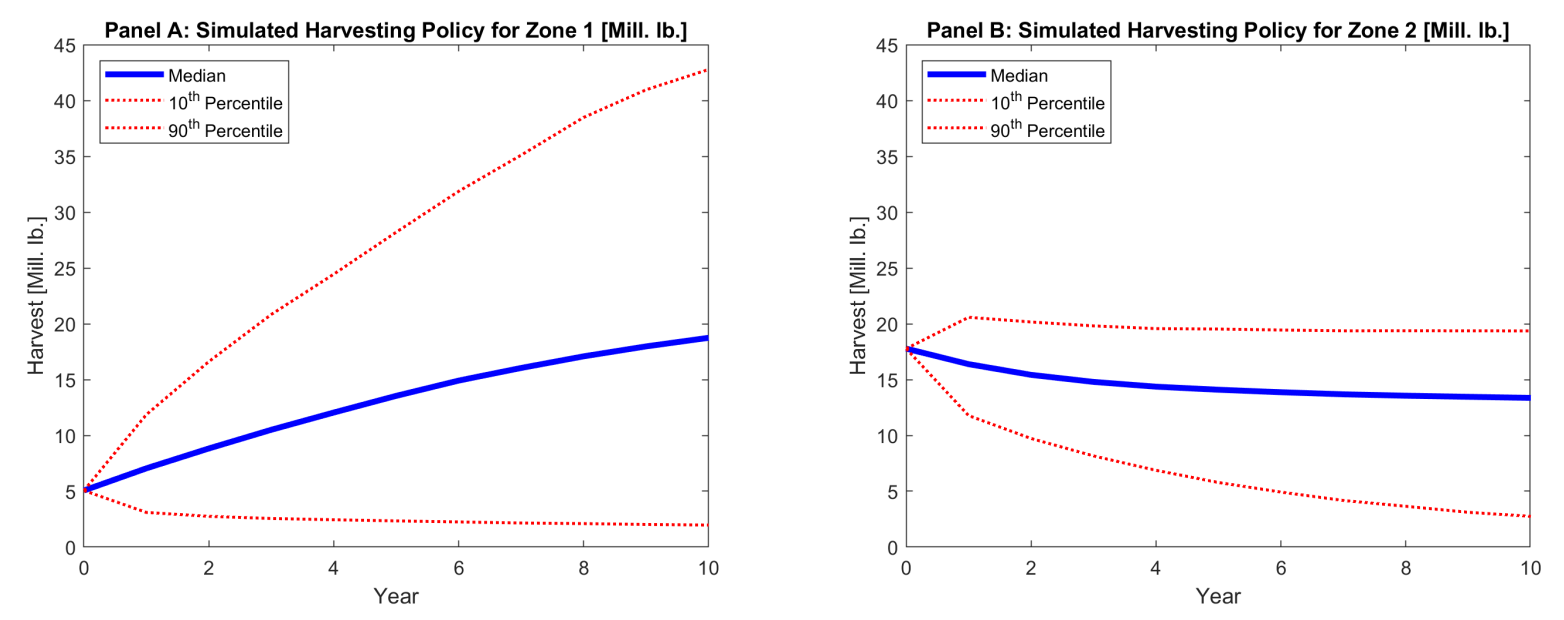

Figure 26: Zone 1: Alaska (2C, 3 and 4) and Zone 2: British Columbia (2B) Simulated Harvesting. Source: Own Elaboration Based on Model Simulations.

Panel A of Figure 26 shows that the simulated harvest in Zone 1: Alaska (2C, 3 and 4 ) is expected to increase significantly over the 10-year horizon. This increase is interesting considering that the biomass is expected to grow over the same period. In particular, this shows that the fishery will optimally allow the biomass to increase over the first years, to be able to optimally increase harvest in the future. Panel B of Figure 26 shows the simulated harvest in Zone 2: British Columbia (2B). In this zone, the harvest will start at a higher level and is expected to decrease over time. This high level of harvesting in Zone 2 explains the observed reduction in biomass.

We notice that the initial simulated harvest in Zone 1: Alaska (2C, 3 and 4) is lower than in Zone 2: British Columbia (2B), although its biomass level is significantly higher. Several characteristics of Zone 1 may help us explain this result. First, the biomass in that zone although greater than the biomass in British Columbia, is relatively small in comparison to the zone's carrying capacity $\left(I_{1}^{\max }=1,146\right)$, therefore, it will be optimal to allow the biomass to grow given the zone's available capacity. Second, the intrinsic growth rate in this zone is small $\left(\gamma_{1}=0.08\right)$ in comparison to the growth rate in British Columbia $\left(\left(\gamma_{2}=0.77\right)\right.$. Thus, to induce biomass growth, the harvesting in Zone 1 must be drastically reduced. Finally, we can also point that the harvesting is only smaller in Alaska at the start of the simulation. As the biomass starts to grow in future simulated periods, the harvesting in the zone also increases, surpassing the harvest in British Columbia. This increment in the harvest is limited though, due to the negative slope of the global demand, as more harvest negatively affects the global prices.

Figure 27 presents the median, $10^{\text {th }}$ and $90^{\text {th }}$ percentile of the simulated aggregated harvesting and global price over the 10-year horizon simulated. 

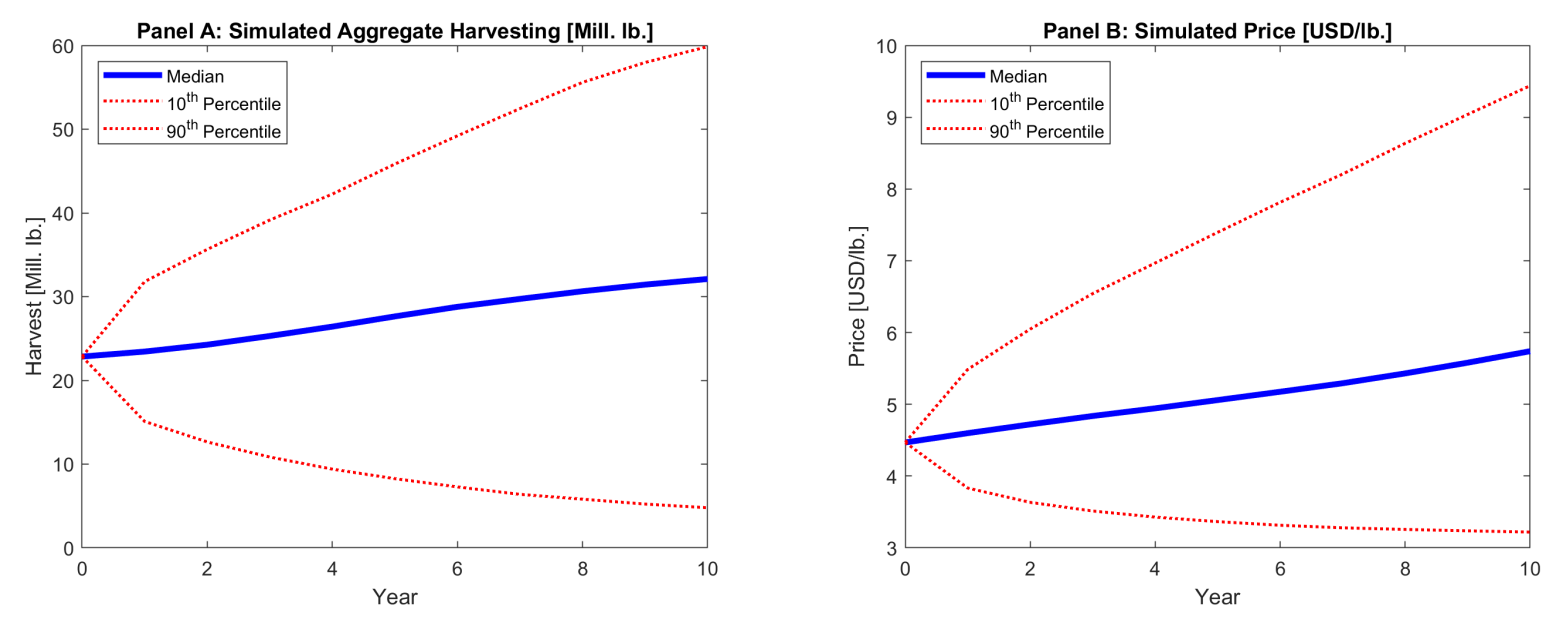

Figure 27: Zone 1: Alaska (2C, 3 and 4) and Zone 2: British Columbia (2B) Simulated Aggregate Harvest and Global Market Price. Source: Own Elaboration Based on Model Simulations.

Panel A of Figure 27]shows that the simulated aggregate harvesting is expected to increase, due specifically to the increment in the harvesting of Zone 1. Beyond the increment in the harvest, prices are also expected to increase over time. This is due to the expected growth in the exogenous demand factor $X_{t}$. An interesting feature of the simulated price dynamics of the Asymmetric case is that prices appear to be more volatile in this case than in the Symmetric Case. This feature may be explained by the asymmetry in the biomass, as Zone 1 will change its production reflecting shocks to its biomass, while not giving significant weight to the harvesting in Zone 2, therefore transferring part of its biomass uncertainty to the global price.

\section{The Impact of a Global Competition}

Our model provides an ideal setting to compare a global framework with an alternative where the individual zones are aggregated into a single optimizing fishery, thus abstracting from all competition effects.

To formulate this comparison, we start by adding the biomass and harvest of South Alaska (2C) and British Columbia (2B). With these time series, we estimate the aggregate biomass dynamics parameters. As we consider both zones simultaneously, the price dynamics will be the same as in the symmetric case. We also update the cost function parameters to reflect the new representative fishery, for this, we consider the total revenue and harvest of South Alaska (2C) and British Columbia (2B) and followed the approach described in Section 3 . We denote the aggregate model as the Single Fishery Case. This model is solved following Pizarro and Schwartz (2021) while incorporating the presented global market. We use the obtained optimal policies to simulate the dynamics of the aggregate harvesting and biomass 
for this case.

All simulations start from the current state of the exogenous demand factor $X_{0}=11.45$ and the biomass: $I_{1,0}=81.18$ million pounds in Zone 1 (South Alaska $(2 \mathrm{C})$ ) and $I_{2,0}=55.04$ million pounds in Zone 2 (British Columbia (2B)).

Figure 28 shows the median, $10^{\text {th }}$ and $90^{\text {th }}$ percentile of 10,000 simulated paths, over a 10-year horizon, for the aggregate biomass in the Symmetric Case and the Single Fishery Case.

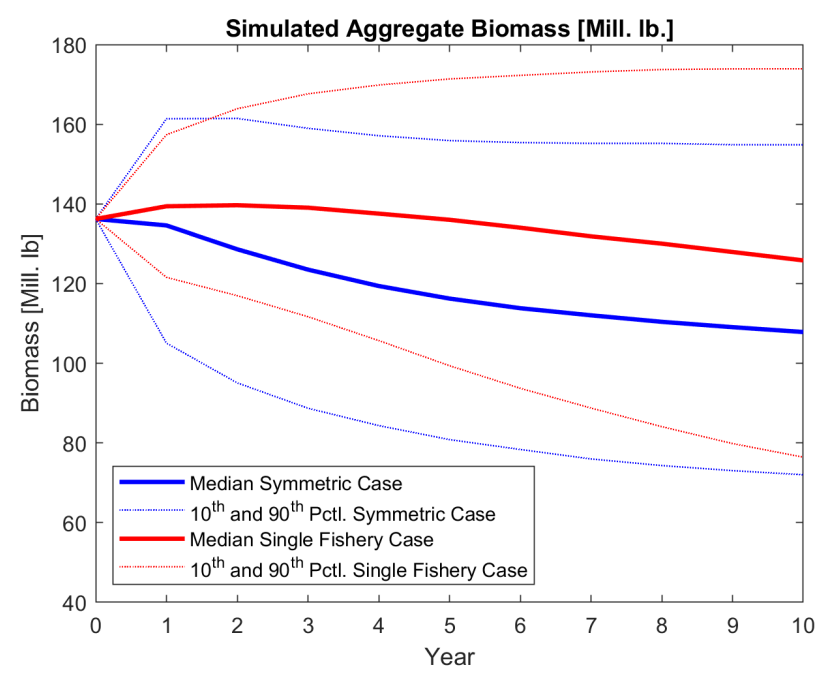

Figure 28: Simulated Aggregate Biomass for the Single Fishery Case and the Symmetric Case. Source: Own Elaboration Based on Model Results.

Figure 28 shows that the biomass is expected to decrease in both cases, but it will be higher in the Single Fishery Case. This figure also shows the biomass in the Single Fishery Case will have a higher $10^{\text {th }}$ and $90^{\text {th }}$ percentiles. The $90^{\text {th }}$ percent percentile shows that in paths of biomass growth will approach its carrying capacity (for the Single Fishery Case $I^{\max }=185$ million pounds).

Figure 29 shows the median, $10^{\text {th }}$ and $90^{\text {th }}$ percentile of the simulated aggregate harvesting for the Symmetric Case and the Single Fishery Case. 


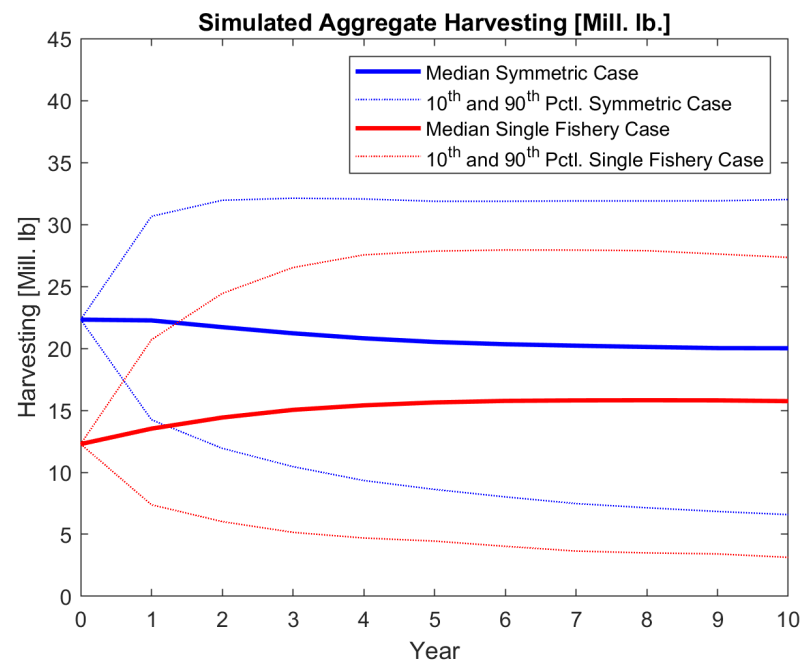

Figure 29: Simulated Aggregate Harvesting for the Single Fishery Case and the Symmetric Case. Source: Own Elaboration Based on Model Results.

Figure 29 shows that the harvest is expected to increase in the Single Fishery Case and decrease in the Symmetric Case, but the harvest in the Single Fishery Case is always lower than in the Symmetric Case. Thus, if each fishery solves the problem individually, it will harvest less over the simulated horizon. This policy is consistent with the higher biomass observed in Figure 29 and will induce also higher global prices, as presented in Figure 30.

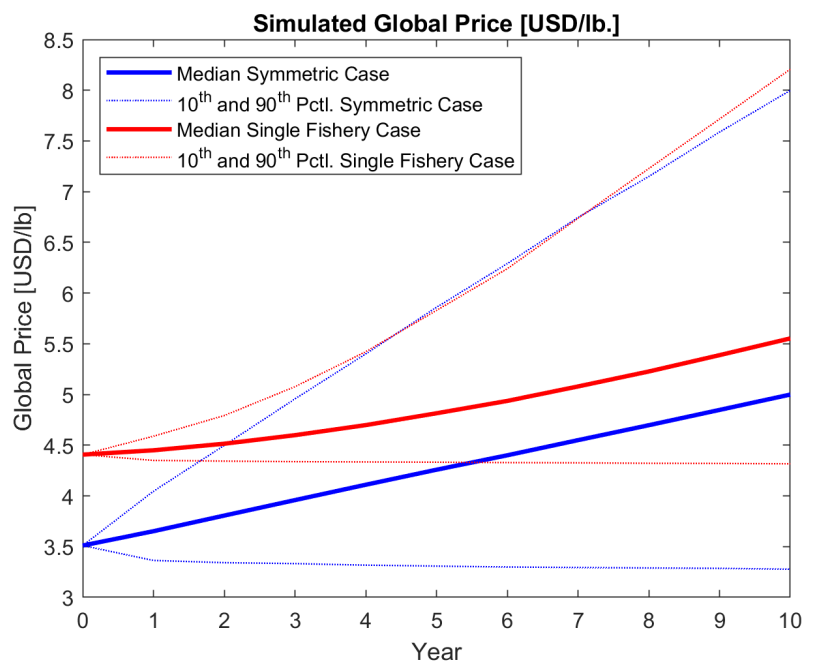

Figure 30: Simulated Global Price for the Single Fishery Case and the Symmetric Case. Source: Own Elaboration Based on Model Results.

Figure 30 shows that the global price is expected to increase in both cases, but it will be higher in the Single Fishery Case for the whole simulated period. This result is consistent with the observed harvesting policy, as the Single Fishery Case harvests less, causing the price to increase. 
Overall, the simulated dynamics are significantly different for the considered cases. In particular, we can conclude that competition will increase the global harvest, and consequently reduced the resource price, overall benefiting consumers. We also notice that this benefit to the consumer will not take a significant toll on the biomass of the aggregate area.

\section{Conclusions}

This article develops and implements a stochastic optimal control approach to a real group of fisheries in defined geographical zones, facing local and global sources of uncertainty. The solution of the model is obtained by solving for the optimal value of the fisheries using a value-function iteration approach. Overall, the results highlight the strong interaction between zones when considering competition in a global market.

The solution is implemented using estimated parameters for the Alaska and British Columbia halibut fishery. We illustrate the model considering a setting with only two zones. In particular, we focus on a Symmetric Case and an Asymmetric Case.

In the Symmetric Case, we consider two zones with comparable biomass, South Alaska (2C) and British Columbia (2B). We find that the optimal harvesting policy, the biomass dynamics and the global prices are significantly influenced by the interaction between the two zones. We also show that specific characteristics of the biomass dynamics in each zone will have an impact on the results.

In the Asymmetric Case, we consider two zones with very different biomass, Alaska (2C, 3 and 4) and British Columbia (2B). We find that the harvesting policy in the larger zone will not be greatly affected by the harvesting policy of the smaller zone. In this setting, the interaction between zones is mostly driven by the policy in the smaller zone.

We use our model to show that global competition is a fundamental force driving a fishery's optimal harvest choices. To reach this conclusion, we compare our Symmetric Case with an alternative where the individual zones are aggregated into a single optimizing fishery (Single Fishery Case), thus abstracting from all competition effects. We show that results are significantly different in each case. We conclude that competition will increase the global harvest and consequently reduced the resource price, overall benefiting consumers.

This paper contributes to the literature by proposing a novel framework to study the interactions of multiple fisheries in a global setting. The model allows us to answer fundamental economic questions, such as how significant is the interaction between fisheries and what is the impact of global competition in the optimal policy. These results have relevant policy implications, as regulators could use the model to determine the total annual catch (TAC) in a multiple zones setting, properly accounting for the interactions shown in our 
results.

In this paper we have concentrated on a single fish specie, abstracting from the interaction in the demand and the supply of different species. These interactions considerably increase the complexity of the problem but look promising topics for future research. 


\section{References}

S. F. Kvamsdal, D. Poudel, and L. K. Sandal. Harvesting in a fishery with stochastic growth and a mean-reverting price. Environmental and resource economics, 63(3):643-663, 2016.

S. Nelson. Pacific Commercial Fishing Fleet: Financial Profiles for 200\%. Fisheries and Oceans Canada (DFO), 2009.

S. Nelson. Pacific Commercial Fishing Fleet: Financial Profiles for 2009. Fisheries and Oceans Canada (DFO), 2011.

L. Nøstbakken. Regime switching in a fishery with stochastic stock and price. Journal of Environmental Economics and Management, 51(2):231-241, 2006.

R. S. Pindyck. Uncertainty in the theory of renewable resource markets. The Review of Economic Studies, 51(2):289-303, 1984.

J. Pizarro and E. Schwartz. Fisheries optimal harvest under price and biomass uncertainty. Environmental and Resource Economics, 78(1), 2021.

D. Poudel, L. K. Sandal, S. F. Kvamsdal, and S. I. Steinshamn. Fisheries management under irreversible investment: does stochasticity matter? Marine Resource Economics, 28(1): 83-103, 2013.

C. Sims, R. D. Horan, and B. Meadows. Come on feel the noise: Ecological foundations in stochastic bioeconomic models. Natural Resource Modeling, 31(4), 2018.

I. Stewart and A. Hicks. Assessment of the Pacific halibut (Hippoglossus stenolepis) stock at the end of 201\%. International Pacific Halibut Commission, 2017.

I. Stewart and R. Webster. Overview of data sources for the Pacific halibut stock assessment, harvest strategy policy, and related analyses. International Pacific Halibut Commission, 2017. 


\section{Appendix A: Implementation of the Model and Value- Function Algorithm Scheme}

\section{Value-Function Iteration Approach}

To solve the Bellman equation for the fishery's value $V_{i}\left(I_{1, t}, \ldots, I_{N, t}, X_{t}\right)$, we follow a modified version of the Value-Function Iteration Approach as presented in Pizarro and Schwartz (2021).

We start from Equation (15) for zone $i$ :

$$
\begin{aligned}
V_{i}\left(I_{1, t}, \ldots, I_{N, t}, X_{t}\right)=\max _{q_{i}^{*} \geq 0}\left\{\pi\left(I_{1, t}, \ldots, I_{N, t}, X_{t}, q_{i}^{*}\left(I_{1, t}, \ldots, I_{N, t}, X_{t}\right)\right)+\right. \\
\left.\frac{1}{1+r} \mathbb{E}_{t}\left[V_{i}\left(I_{1, t+1}, \ldots, I_{N, t+1}, X_{t+1}\right) \mid I_{1, t}, \ldots, I_{N, t}, X_{t}\right]\right\}
\end{aligned}
$$

where $q_{i}^{*}\left(I_{1, t}, \ldots, I_{N, t}, X_{t}\right)$ is the harvesting policy and $\left\{I_{1, t+1}, \ldots, I_{N, t+1}, X_{t+1}\right\}$ is the state at year $t+1$ of the stochastic variables in our model, the resource biomass for each zones and the exogenous demand factor.

We solve Equation (26) assuming that the fishery in zone $i$ maximizes taking the set of optimal policies for the rest of the considered zones, $q^{*} / q_{i}^{*}$, as known. This set of functions is fundamental to solve the Bellman equation as it allows the calculation of the period's profits and the expected state of all the zones' biomass in the following period, and consequently, the continuation value.

The model implementation starts by defining a discrete state space for the biomass of each zone in the set $i \in\{1,2, . ., N\}$ and the exogenous demand factor, $\left\{I_{1, m_{1}}, \ldots, I_{N, m_{N}}, X_{j}\right\}$, where $I_{i, m_{i}} \in\left\{I_{i, 1}, I_{i, 2}, \ldots, I_{i, M}=I_{i}^{\max }\right\}$ and $X_{j} \in\left\{X_{1}, X_{2}, \ldots, X_{J}\right\}$.

The optimal control for each zone is also discretized to the set $q_{i, k_{i}} \in\left\{q_{i, 1}=q_{i}^{\text {min }}, \ldots, q_{i, K}=\right.$ $\left.q_{i}^{\max }\right\}$. Over the state space the function $V^{i}=V_{m_{1}, \ldots, m_{N}, j}^{i}$ is a $N^{M} \times J$ matrix representing the value of the fishery in zone $i$ for the state $\left\{I_{1, m_{1}}, \ldots, I_{N, m_{N}}, X_{j}\right\}$.

The shocks to the biomass of each zone and the exogenous demand factor are denoted by $Z^{i} \quad i \in\{1, \ldots, N\}$ and $Z^{X}$ respectively. The global biomass shock is denoted $Z^{G}$. These shocks are assumed to be i.i.d. standard normal random variables. The shocks discretization transforms them into finite Markov chains $Z_{f_{i}}^{i} \in\left\{Z_{1}^{i}, Z_{2}^{i}, \ldots, Z_{F}^{i}\right\}$ for all $i \in\{1, \ldots, N\}$, $Z_{h}^{X} \in\left\{Z_{1}^{X}, Z_{2}^{X}, \ldots, Z_{H}^{X}\right\}$ and $Z_{u}^{G} \in\left\{Z_{1}^{G}, Z_{2}^{G}, \ldots, Z_{U}^{G}\right\}$, for the biomass of each zone, the exogenous demand factor and the global biomass shock respectively.

$\lambda_{f_{i}}^{i}$ is the transition probability from the current biomass shock $Z_{0}^{i}$ to a biomass shock 
$Z_{f_{i}}^{i}$ in the following period. For the exogenous demand shock, $\lambda_{g}^{X}$ represents the transition probability from the current exogenous demand shock $Z_{0}^{X}$ to a demand shock $Z_{h}^{X}$. Finally, for the global biomass shock, $\lambda_{u}^{G}$ is the transition probability from the global biomass shock $Z_{0}^{G}$ to a shock $Z_{u}^{G}$.

Using the discretization of the state space, value function, harvesting policies and shocks, Equation $(26)$ can then be re-written as:

$$
\begin{gathered}
V_{m_{1}, \ldots, m_{N}, j}^{i}=\max _{q_{i, k_{i}} \in\left\{q_{i, 1}, \ldots, q_{i, K}\right\}}\left\{\pi\left(I_{1, m_{1}}, I_{2, m_{2}}, \ldots, I_{N, m_{N}}, X_{j}, q_{i, k_{i}}\right)+\right. \\
\left.\frac{1}{1+r} \sum_{f_{1}=1}^{F} \ldots \sum_{f_{N}=1}^{F} \sum_{u=1}^{U} \sum_{h=1}^{H}\left[\prod_{i=1}^{N} \lambda_{f_{i}}^{i}\right] \times \lambda_{u}^{G} \times \lambda_{h}^{X} \times V^{i}\left(I_{1, m_{1}}+\Delta I_{1, m_{1}}, \ldots, I_{N, m_{N}}+\Delta I_{N, m_{N}}, X_{j}+\Delta X_{j}\right)\right\}
\end{gathered}
$$

where $I_{m_{i}}+\Delta I_{m_{i}}$ for all $i \in\{1,2, \ldots, N\}$ and $X_{j}+\Delta X_{j}$ are the state of the biomass of each zone and exogenous demand factor in the next period.

These values are calculated using the stochastic processes defined in Equations (1), (4), (9) and (10) for the biomass and the exogenous demand factor.

For the set of optimal policies is $q^{*}$ and stochastic shocks $\left\{Z_{f_{1}}^{1}, \ldots, Z_{f_{N}}^{N}, Z_{u}^{G}, Z_{h}^{X}\right\}$, the next period biomass state for zone $i$ is:

$$
I_{i, m_{i}}+\Delta I_{i, m_{i}}=I_{i, m_{i}}+\gamma^{i} I_{i, m_{i}}\left(1-\frac{I_{i, m_{i}}}{I_{\text {max }}^{i}}\right)-q_{i}^{*}\left(m_{1}, \ldots, m_{N}, j\right)+I_{i, m_{i}} \times\left[\sigma^{i} \times Z_{f_{i}}^{i}+\phi \times Z_{u}^{G}\right]
$$

The next period exogenous demand factor is:

$$
X_{j}+\Delta X_{j}=X_{j} e^{\mu_{X}+\sigma_{X} Z_{h}^{X}}
$$

The solution algorithm starts from guesses of the value function $V^{0, i}=V_{m_{1}, \ldots, m_{N}, j}^{i}$ and the set of optimal policies $q^{0, *}$. First, for each zone $i \in\{1,2, \ldots, N\}$ individually, the algorithm iterates over each point of the state space $\left\{I_{1, m_{1}}, \ldots, I_{N, m_{N}}, X_{j}\right\}$. In each of these states, the right-hand-side of Equation (27) is maximized using the stochastic optimal control $q_{i, k_{i}}$. If the optimized value of the current iteration is greater than the current value function for the state, then the old value function is replaced by the newly maximized value and the optimal policy of the zone $i$ is replaced by the respective harvest. The process is repeated until no significant changes are made to the value function in the latter iteration.

After the value-maximization procedure is finished for all the zones, the set $q^{0, *}$ is updated with the newly computed optimal policies. Using this updated set of policies $q^{1, *}$, the valuemaximization procedure is repeated for all zones. This method is repeated until no significant 
changes in the optimal set of policies are made in the latter global iteration. 